Article

\title{
Optimal Scheduling of Hydro-Thermal-Wind-Photovoltaic Generation Using Lightning Attachment Procedure Optimizer
}

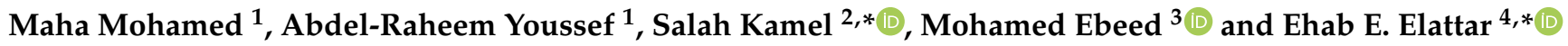 \\ 1 Department of Electrical Engineering, Faculty of Engineering, South Valley University, Qena 83523, Egypt; \\ mahamohamed21@yahoo.com (M.M.); abou_radwan@hotmail.com (A.-R.Y.) \\ 2 Department of Electrical Engineering, Faculty of Engineering, Aswan University, Aswan 81542, Egypt \\ 3 Department of Electrical Engineering, Faculty of Engineering, Sohag University, Sohag 82524, Egypt; \\ mebeed@eng.sohag.edu.eg \\ 4 Department of Electrical Engineering, College of Engineering, Taif University, P.O. Box 11099, \\ Taif 21944, Saudi Arabia \\ * Correspondence: skamel@aswu.edu.eg (S.K.); e.elattar@tu.edu.sa (E.E.E.)
}

Citation: Mohamed, M.; Youssef, A.-R.; Kamel, S.; Ebeed, M.; Elattar, E.E. Optimal Scheduling of Hydro-Thermal-Wind-Photovoltaic Generation Using Lightning Attachment Procedure Optimizer. Sustainability 2021, 13, 8846. https:// doi.org/10.3390/su13168846

Academic Editor: Domenico Mazzeo

Received: 5 June 2021

Accepted: 28 July 2021

Published: 7 August 2021

Publisher's Note: MDPI stays neutral with regard to jurisdictional claims in published maps and institutional affiliations.

Copyright: (c) 2021 by the authors. Licensee MDPI, Basel, Switzerland. This article is an open access article distributed under the terms and conditions of the Creative Commons Attribution (CC BY) license (https:// creativecommons.org/licenses/by/ $4.0 /)$.

\begin{abstract}
This paper presents an effective solution for the short-term hydrothermal generation scheduling (STHS) problem using an integration of wind and photovoltaic power (PV) system. Wind and PV power are integrated into the power system to minimize the total fuel cost of thermal units. In this paper, the lightning attachment procedure optimization algorithm (LAPO) is employed to solve the STHS problem using the wind and PV power integration system. The proposed method is applied for solving five test systems with different characteristics, considering the valve-point loading impact of the thermal unit. The first and third test systems include hydro and thermal units only, and the rest of the systems consist of hydro and thermal units with integrating wind and PV power-generating units to inspect the effect of renewable energy sources in the selected test systems. The simulation results are compared with other studied methods. It is found that the proposed method is superior, and it has the ability to obtain the best solutions with respect to other optimization methods that are implemented to solve the STHS problem.
\end{abstract}

Keywords: hydrothermal generation scheduling; wind and photovoltaic power; optimization; LAPO algorithm

\section{Introduction}

In recent years, the demand for electric power has increased, and fossil fuel prices have risen rapidly, which has led to growing the energy crisis in the world. Therefore, the world has tended to reduce the use of thermal units by using renewable energy sources to reduce the polluting emissions and harmful gases that are released from thermal units when fossil fuels are burnt. These harmful gases have a negative effect on the environment, and this leads to an increase in the temperature of the planet, which causes global warming. Renewable energy sources, mainly wind and solar, are very cost-effective as well as ecofriendly to the environment. Therefore, the incorporation of the short-term hydrothermal generation scheduling (STHS) problem and renewable energy has great importance in the power system operation. The STHS problem is one of the most important optimization problems in the power system network. The primary goal of the STHS problem is to determine the optimal power-generation schedule of the thermal and hydro units to minimize the total operation cost of the system.

The STHS is subjected to a variety of constraints related to the hydraulic and thermal units, which include power load balance, power-generation limits, reservoir volume limits, and water discharge rate limits. These constraints with the valve-point loading impact make this problem a non-linear and complicated optimization problem. Several analytical optimization methods have been employed such as dynamic programming (DP) [1], 
mixed-integer linear programming [2], nonlinear programming (NLP) [3], and Lagrange relaxation (LR) [4]. It should be highlighted here that these methods suffer from stagnation, and they are not able to provide the optimal solution due to the nonlinearity and composite constraints of the STHS problem. Thus, several modern heuristic and meta-heuristic optimization methods have been applied to solve the STHS problem to avoid stagnation of the analytical methods, such as the genetic algorithm (GA) [5], differential evolution (DE) [6], particle swarm optimization (PSO) [7], teaching-learning-based optimization (TLBO) [8], and artificial bee colony (ABC) [9]. An improved harmony search (IHS) optimization algorithm has been introduced in [10] to find the optimal solution to the short-term hydrothermal scheduling problem. In this reference, the proposed method has been employed on two test systems with different constraints including the valve-point loading impact and transmission losses. A modified dynamic neighborhood learning-based particle swarm optimization (MDNLPSO) method has been introduced in [11] to solve the STHS problem considering the valve-point loading impact and the power transmission loss. A real-coded genetic algorithm based on the improved Mühlenbein mutation (RCGA-IMM) algorithm has been applied by Nazari-Heris et al. [12] to solve the STHS problem and minimize the total cost of the hydrothermal system. A differential real-coded quantum-inspired evolutionary algorithm (DRQEA) has been introduced in [13] to solve the STHS problem considering the valve-point loading impact and the power transmission loss.

Renewable energy sources such as wind and PV power have a great important role in many countries as these sources have low cost and produce electric power without any harmful emissions. Hence, the integration of renewable energy resources into the electrical grid attracts more attention from researchers.

Few efforts have been presented to study the effect of inclusion of renewable energy sources such as wind and solar energy in a short-term hydrothermal system. Zhang et al. [14] applied a gradient-based multi-objective cultural differential evolution (GDMOCDE) to solve the STHS problem and minimize the generation cost and emission of thermal plants. Banerjee et al. [15] solved the SHTS problem considering the wind power by using the particle swarm optimization technique (PSO). In 2016, Dubey et al. [16] applied the ant lion optimization algorithm (ALO) to solve the short-term hydrothermal scheduling problem considering the wind speed uncertainty.

A hydro-thermal-wind scheduling problem and wind uncertainty were presented in [17]. In this reference, an extended NSGA-III algorithm was proposed to obtain the optimal Pareto solutions of the multi-objective optimization problem. An enhanced multiobjective bee colony optimization algorithm (EMOBCO) has been proposed in [18] to solve short-term hydro-thermal-wind complementary scheduling considering the uncertainty of wind power. Multi-objective complementary scheduling of the hydro-thermal-RE power system has been presented in [19] to solve the STHS problem, taking both cost and emission objectives and considering the uncertainty of wind power, and a multi-objective hybrid grey wolf optimizer was proposed to solve this problem. Table 1 presents the definitions of test systems applied to solve the STHS problem with integration of wind and PV power. Different optimization methods used to solve the STHS problem with integration of wind and photovoltaic power are summarized in Table 2.

Lightning attachment procedure optimization (LAPO) is a novel algorithm proposed by A.F. Nematollahi et al. [20,21]. LAPO has simulated the lightning attachment process in nature. LAPO is based on five steps, which are air breakdown on the cloud edge, downward leader movement toward the ground, branch fading, upward leader propagation, and the strike point, which mimics the optimal solution. LAPO has a high searching capability that has been applied to solve several optimization problems. In [22], LAPO has been applied to determine the optimal siting and sizing of the unified power flow controller in the transmission system. Y. Heba et al. solved the optimal power flow using the LAPO technique [23]. In [24], the LAPO technique was employed to determine the optimal location and size of the distributed generators in the distribution network. W. Lui et al. presented the LAPO to optimize the image segmentation in [25]. 
Table 1. Definition of test systems applied to solve the STHS problem with integration of wind and PV power.

\begin{tabular}{ll}
\hline \multicolumn{1}{c}{ Test System } & \multicolumn{1}{c}{ Number of Hydrothermal Generation Units } \\
\hline Test System $\mathbf{1}$ & Four cascaded hydropower plants and three thermal plants \\
\hline Test System $\mathbf{2}$ & $\begin{array}{l}\text { Four cascaded hydropower plants, three thermal plants, and } \\
\text { one equivalent wind-and-solar-generating unit }\end{array}$ \\
\hline Test System 3 & Four hydro plants and ten thermal plants \\
\hline Test System 4 & $\begin{array}{l}\text { Four cascaded hydropower plants, eight thermal-power } \\
\text { plants, and one equivalent wind- and equivalent } \\
\text { solar-generating unit }\end{array}$ \\
\hline Test System 5 & $\begin{array}{l}\text { Four cascaded hydropower plants, eight thermal-power } \\
\text { plants, and two wind-generating units }\end{array}$ \\
\hline
\end{tabular}

In this paper, the authors present the lightning attachment procedure optimization (LAPO) technique to find the hourly optimal power generation of thermal units and hydropower units to minimize the total fuel cost and the total emissions. The effect of wind and photovoltaic generation systems is taken into consideration to find the optimal solution of the STHS optimization problem. To evaluate the performance of the developed algorithm, it is applied to five test systems including four hydropower plants with three thermal units, four cascaded hydropower plants with three thermal plants and one equivalent wind-and-solar-generating unit, four hydro plants with ten thermal units, four cascaded hydropower plants and eight thermal-power plants and one equivalent wind and equivalent solar-generating unit, and four hydro plants with eight thermal units and two wind generation units.

The main contributions of this paper can be depicted as follows:

- The hydro-thermal generation scheduling problem is solved for small and large test systems.

- The renewable energy resources including the wind and PV generation systems are considered in the STHS problem.

- The economic issues are considered with cost reduction in the STHS problem.

- Application of efficient optimizer called LAPO to solve the STHS problem with renewable energy resources.

The rest of this paper is organized as follows: The problem formulation of hydrothermal generation scheduling with a wind and PV power integration system is introduced in Section 2. The lightning attachment procedure optimization algorithm (LAPO) method is illustrated in Section 3. The simulation results are represented in Section 4. Finally, the conclusion is explained in Section 5. 
Table 2. Summary of the literature review of optimization methods to solve the STHS problem with integration of wind and PV power.

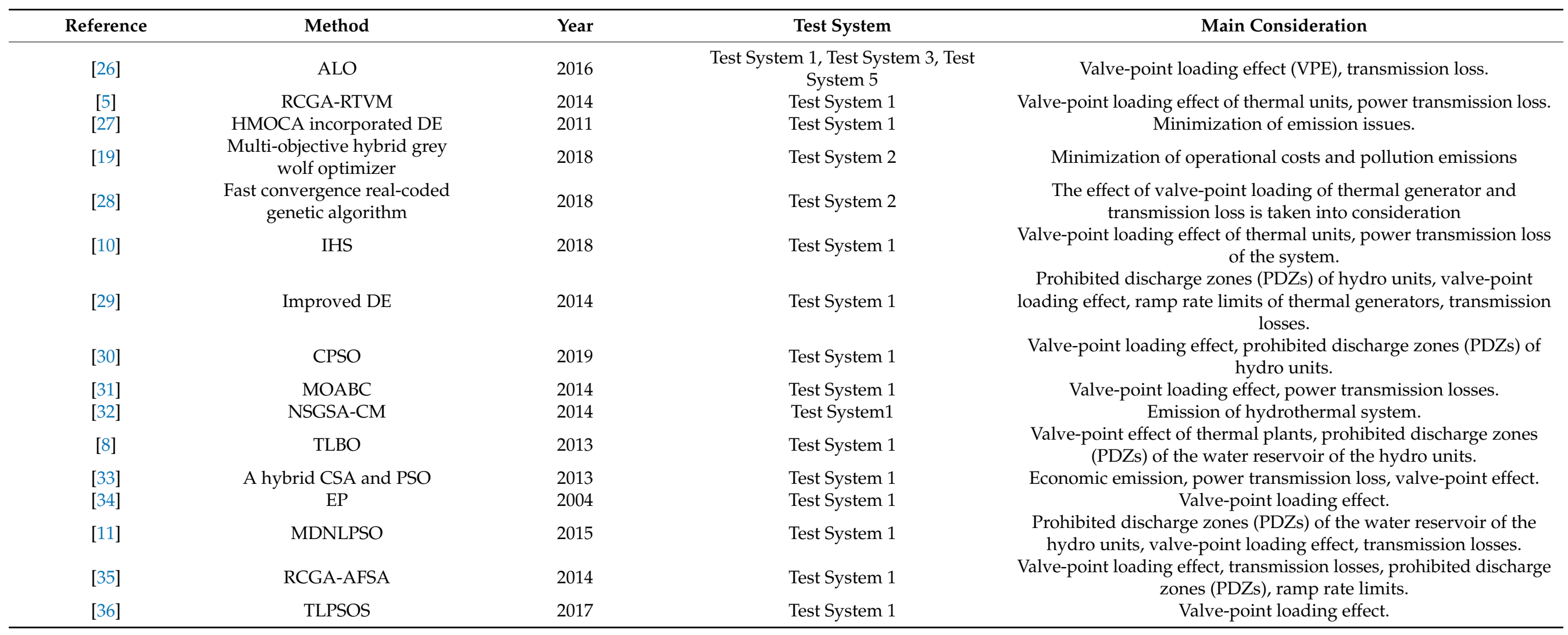




\section{Problem Formulation of Hydrothermal Generation Scheduling with Wind and PV Power Integration System}

The objective of the STHS problem with integration of wind and PV power is to minimize the total fuel cost as well as emission caused by thermal plants considering the cost of wind and PV power while satisfying various constraints. The objective function of the STHS problem with the wind and PV power integration system considering the different constraints is expressed as follows:

\subsection{The Cost Minimization}

$$
F_{1}=\sum_{t=1}^{T}\left\{\sum_{i=1}^{N_{s}} f_{s i}^{t}\left(P_{s i}^{t}\right)+\sum_{k=1}^{N_{w}} f_{w k}^{t}\left(P_{w k}^{t}\right)+\sum_{m=1}^{N_{p v}} f_{p v m}^{t}\left(P_{p v m}^{t}\right)\right\}
$$

where $F_{1}$ is the total operating cost of thermal, wind, and PV power-generating units. $f_{s i}^{t}$ is the total fuel cost of thermal units. $f_{w v k}^{t}$ is the total cost of wind-generating units. $f_{p v m}^{t}$ is the total cost of PV-generating units. The total number of thermal, wind, and PV powergeneration units are $N_{s}, N_{w}$, and $N_{p v}$, respectively. $T$ is the length of the total scheduling period. The output power generation from thermal, wind, and PV power-generation units are $P_{s i}^{t}, P_{w k,}^{t}$, and $P_{p v m}^{t}$, respectively.

The fuel cost of the thermal unit at a time $t$ taking into consideration the valve-point loading effect (VPLE) is represented as follows:

$$
f_{i t}\left(P_{s i t}\right)=\min \sum_{t=1}^{T} \sum_{i=1}^{N_{s}}\left\{a_{i}+b_{i} P_{s i}^{t}+c_{i}\left(P_{s i}^{t}\right)^{2}+\left|d_{i} \sin \left[e_{i}\left(P_{s i}^{\min }-P_{s i}^{t}\right)\right]\right|\right\}
$$

where, $a_{i}, b_{i}, c_{i}, d_{i}$, and $e_{i}$ are the cost coefficients of the thermal unit, and $P_{s i}^{\min }$ is the minimum power-generation limit of the thermal unit.

\subsection{The Emission Rate Minimization}

The STHS problem with integration of wind and PV power aims to minimize the total amount of emissions that are released from thermal units due to the burning of fossil fuels used to produce electricity. The function of the emission rate can be represented as the sum of a quadratic and an exponential function [37]. The total emission produced by thermal units in the system can be expressed as follows:

$$
F_{2}=\min \sum_{t=1}^{T} \sum_{i=1}^{N_{s}}\left\{\alpha_{i}+\beta_{i} P_{s i}^{t}+\gamma_{i}\left(P_{s i}^{t}\right)^{2}+\eta_{i} \exp \left(\delta_{i} P_{s i}^{t}\right)\right\}
$$

where $F_{2}$ is the total amount of emissions. $\alpha_{i}, \beta_{i}, \gamma_{i}, \eta_{i}$, and $\delta_{i}$ are the emission coefficients of the thermal unit.

\subsection{Constraints}

The STHS problem with a wind and PV power integration system should satisfy the following equality and inequality constraints.

(1) power balance constraints

$$
\sum_{i=1}^{N_{s}} P_{s i}^{t}+\sum_{j=1}^{N_{h}} P_{h j}^{t}+\sum_{k=1}^{N_{w v}} P_{w k}^{t}+\sum_{m=1}^{N_{p v}} P_{p v m}^{t}-P_{L}^{t}=P_{D}^{t} . \quad t \in T
$$

where $N_{h}$ is the number of hydropower units. $P_{D}^{t}$ is the power load demand. $P_{h j}^{t}$ is the output power of the hydro unit. $P_{L}^{t}$ is the transmission loss of the system. 
The power generation of hydropower units $P_{h j}^{t}$ can be represented as

$$
P_{h j}^{t}=C_{1 j}\left(V_{h j}^{t}\right)^{2}+C_{2 j}\left(Q_{h j}^{t}\right)^{2}+C_{3 j} V_{h j}^{t} Q_{h j}^{t}+C_{4 j} V_{h j}^{t}+C_{5 j} Q_{h j}^{t}+C_{6 j} \quad j \in N_{h} . t \epsilon T
$$

where $C_{1 j}, C_{2 j}, C_{3 j}, C_{4 j}, C_{5 j}$, and $C_{6 j}$ represent the coefficients of the hydropower-generating units, respectively. $V_{h j}^{t}$ and $Q_{h j}^{t}$ represent the reservoir volume and water release of the hydro unit, respectively.

The power transmission loss $P_{L}^{t}$ can be represented as follows:

$$
P_{L}^{t}=\sum_{i=0}^{N_{h}+N_{s}} \sum_{j=0}^{N_{h}+N_{s}} P_{i}^{t} B_{i j} P_{j}^{t}+\sum_{i=0}^{N_{h}+N_{s}} B_{o i} P_{i}^{j}+B_{o o}
$$

where, $B_{i j}, B_{o i}$, and $B_{o o}$ represent the coefficients of transmission power loss.

(2) Water balance constraint

$$
V_{h j}^{t}=V_{h j}^{t-1}+I_{h j}^{t}-Q_{h j}^{t}-S_{h j}^{t}+\sum_{l=1}^{R_{u j}}\left(Q_{h l}^{t-d_{l j}}+S_{h l}^{t-d_{l j}}\right) . j \epsilon N_{h} . t \in T .
$$

where $I_{h j}^{t}$ and $S_{h j}^{t}$ represent the water inflow and spillage of the hydro plant. $R_{u j}$ is the number of upstream hydropower-generating units above the reservoir.

(3) Initial and terminal reservoir storage volumes and water discharge rate limits

$$
\begin{array}{ll}
V_{h j}^{\min } \leq V_{h j}^{t} \leq V_{h j}^{\max } & , j \in N_{h}, \quad t \in T \\
Q_{h j}^{\min } \leq Q_{h j}^{t} \leq Q_{h j}^{\max } & , j \in N_{h}, \quad t \in T
\end{array}
$$

where $V_{h j}^{\min }$ and $V_{h j}^{\max }$ are the minimum and maximum reservoir storage volumes of hydro units. $Q_{h j}^{\min }$ and $Q_{h j}^{\max }$ are the minimum and maximum water discharge rates of hydro units.

(4) Power generation limits

Each power-generation unit has minimum and maximum output limits.

$$
\begin{aligned}
& P_{h j}^{\min } \leq P_{h j}^{t} \leq P_{h j}^{\max } \quad . j \in N_{h} . \quad t \in T \\
& P_{s i}^{\min } \leq P_{s i}^{t} \leq P_{s i}^{\max } . i \in N_{s} . \quad t \in T . \\
& P_{w k}^{\min } \leq P_{w k}^{t} \leq P_{w k}^{\max } . k \in N_{w} . \quad t \in T . \\
& P_{p v m}^{\min } \leq P_{p v m}^{t} \leq P_{p v m}^{\max } . m \in N_{p v} . \quad t \in T .
\end{aligned}
$$

\subsection{Modeling of Wind and PV Power Generation}

The output power of wind unit [26] for a given wind speed at time $t$ is expressed as follows:

$$
\begin{gathered}
f_{w k}^{t}\left(P_{w k}^{t}\right)=\sum_{k=1}^{N_{w}} K_{w k} P_{w k}^{t} \\
P_{w k}^{t}=\left\{\begin{array}{cc}
0 & \text { for } v_{w}^{t}<v_{\text {in }}, v_{w}^{t}>v_{\text {out }} \\
P_{w r k}^{t} *\left(\frac{v_{w}^{t}-v_{i n}}{v_{r}-v_{i n}}\right) & \text { for } v_{\text {in }} \leq v_{w}^{t} \leq v_{r} \\
P_{w r k} & \text { for } v_{r} \leq v_{w}^{t} \leq v_{\text {out }}
\end{array}\right\}
\end{gathered}
$$

where $v_{\text {in }}, v_{\text {out }}$, and $v_{r}$ are the cut-in, cut-out, and rated wind speeds, respectively. $P_{w r k}^{t}$ is the rated power of the wind unit. 
The output power of PV unit [28] at time $t$ is expressed as follows:

$$
\begin{aligned}
& f_{p v m}^{t}\left(P_{p v m}^{t}\right)=\sum_{m=1}^{N_{p v}} P_{p v m}^{t} K_{s m} \\
& P_{p v m}^{t}=\left\{\begin{array}{l}
P_{s r}\left(\frac{G^{2}}{G_{s t d}} R_{C}\right) \quad \text { for } 0<G<R_{C} \\
P_{s r}\left(\frac{G^{2}}{G_{s t d}}\right) \quad \text { for } \quad G>R_{C}
\end{array}\right\}
\end{aligned}
$$

where $G$ denotes the forecast solar radiation at a time $t . G_{s t d}$ is the solar radiation in the standard environment set as $1000 \mathrm{w} / \mathrm{m}^{2} . R_{C}$ is a certain radiation point set as $150 \mathrm{w} / \mathrm{m}^{2}$. $P_{s r}$ denotes the rated power output of the PV unit.

\section{Lightning Attachment Procedure Optimization (LAPO)}

Lightning attachment procedure optimization (LAPO) is a new efficient optimization algorithm that mimics the lightning phenomena procedure in nature. The lightning is formed due to the cumulation of a high number of charges in the clouds. The continuous increase in the number of charges leads to an increase in the electrical strength and breakdown of air; consequently, several downloaders are formed, starting from the downside of the cloud, as shown in Figure 1. The down leaders are combined with the upward leaders at the strike point from the lightning.
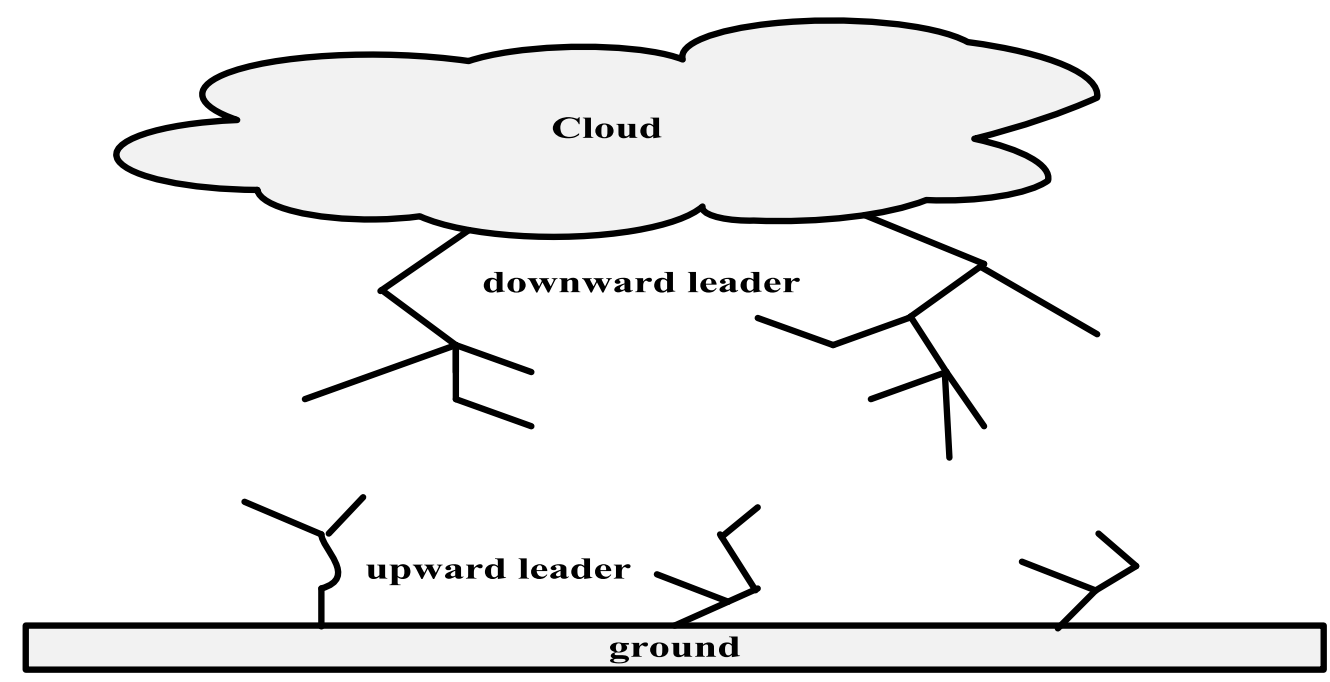

Figure 1. The charge distribution in a cloud.

LAPO is based on five step ladders including (1) air breakdown that closed to the cloud surface (2), the orientation of the lightning downward leaders, (2) branch fading, (3) extension of the upward leaders (4), and strike point position (5).

\section{Mathematical Model of LAPO}

\section{Step 1: Trail spots}

The trial spots are the initial downward leaders' starting points, which are evaluated as follows:

$$
X_{s}^{h}=X_{\min }^{h}+\operatorname{rand} \times\left(X_{\max }^{h}-X_{\min }^{h}\right)
$$

where $X_{s}^{h}$ represents the initial position of the downward leader or the trial spot. $X_{\text {min }}$ denotes the minimum limit of the control variable, while $X_{\max }$ denotes the maximum value. 
rand represents a random number within range [26]. The objective functions of the initial positions are evaluated as follows.

$$
F_{s}^{h}=\text { Fitness }\left(X_{s}^{h}\right)
$$

Step 2: The next jumping of the initial points

All initial trial spots are averaged, and their objective function is determined:

$$
\begin{aligned}
& X_{r}=\text { mean }\left(X_{s}^{h}\right) \\
& F_{r}=\operatorname{Fitness}\left(X_{r}\right)
\end{aligned}
$$

$X_{r}$ is the averaged point. $F_{r}$ denotes the fitness function of the mean point. It is well-known that the lightning has many paths to jump to the next location where the lightning will go to a high-voltage point.

To update the point $i$, a random solution $j$ is selected where $i \neq j$. The updated point is jumped to the new location as follows:

$$
\begin{aligned}
& X_{s_{-} \text {new }}^{h}=X_{s}^{h}+\text { rand } \times\left(X_{r}+X_{S}^{j}\right) \quad \text { IF } F_{j}>F_{r} \\
& X_{s_{-} \text {new }}^{i}=X_{s}^{i}-\text { rand } \times\left(X_{r}+X_{S}^{j}\right)
\end{aligned}
$$

\section{Step 3: Branch fading}

The downward leader will be faded if the critical point is more than the electric field of the new point in terms of the objective function value; otherwise, it remains continuous; this fading can be mathematically represented as follows:

$$
\begin{gathered}
X_{s}^{h}=X_{s_{-} \text {new }}^{h} \quad \text { IF } F_{s_{-} \text {new }}^{h}<F_{s}^{h} \\
\text { Otherwise } X_{s_{-} \text {new }}^{i}=X_{s}^{i}
\end{gathered}
$$

\section{Step 4: Upward leader movement}

In this stage, the points move up, which simulates the orientation of the upward leaders, which are distributed exponentially along the channels, which can be modeled as follows:

$$
A=1-\left(\frac{t}{t_{\max }}\right) \times \exp \left(-\frac{t}{t_{\max }}\right)
$$

where $A$ is an exponent operator. $t$ and $t_{\max }$ are the iteration number and the maximum number of iterations. The updated point based on the upward motion is given as follows:

$$
X_{s_{-} \text {new }}^{h}=X_{s_{-} \text {new }}^{h}+\text { rand } \times A \times\left(X_{\text {best }}^{h}-X_{\text {worst }}^{h}\right)
$$

where $X_{\text {best }}^{h}$ and $X_{\text {worst }}^{h}$ denote the best and the worse points among the other points.

\section{Step 5: The strike point}

The lightning operation pauses when the down leader and the up leader gather each other, and the striking point is assigned. The flowchart of the LAPO algorithm for obtaining the optimal solution is shown in Figure 2. 


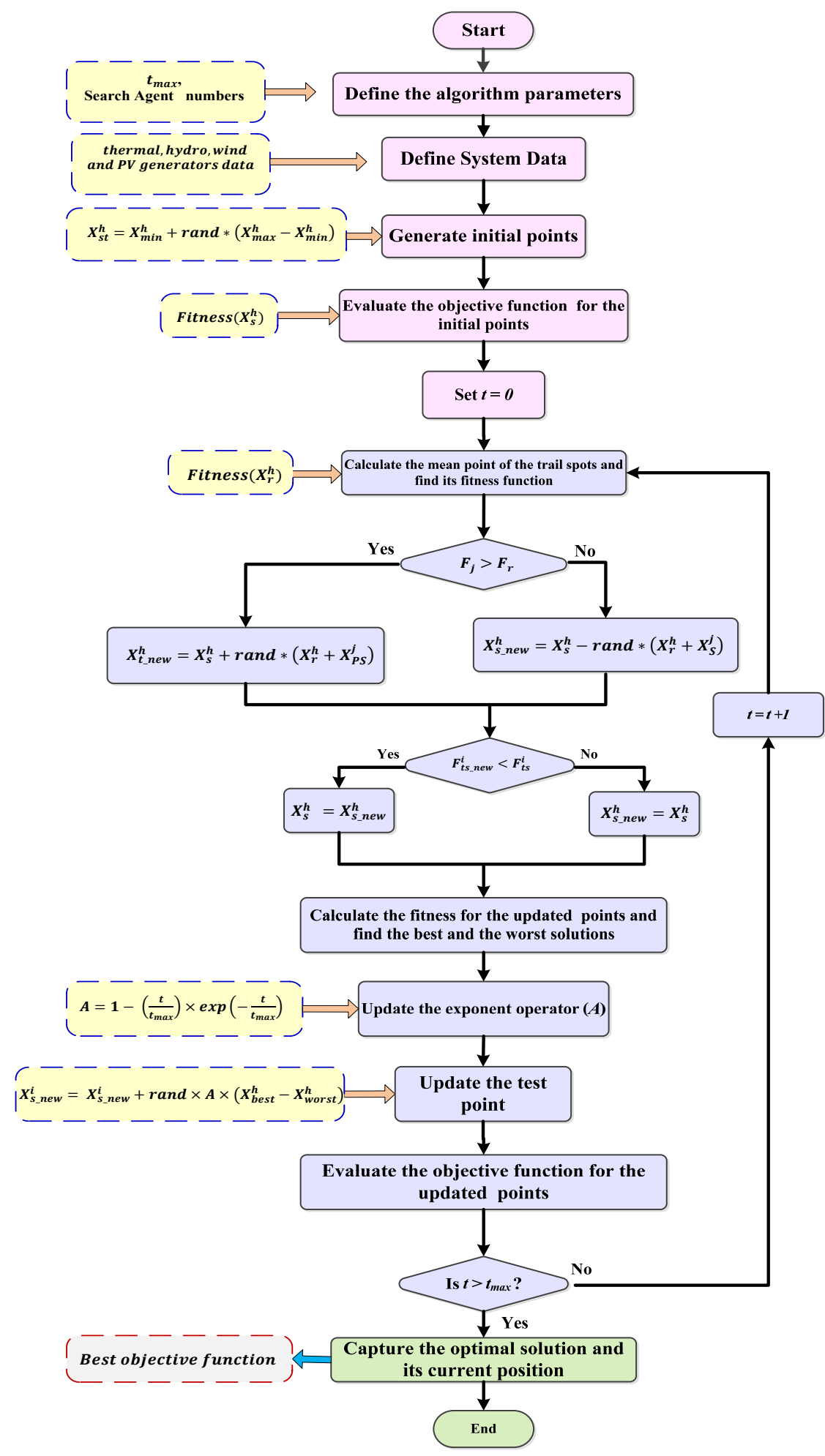

Figure 2. Schematic diagram for STHS problem with wind and PV power integration system using the LAPO algorithm.

\section{Simulation Results and Discussion}

The LAPO algorithm is applied to five hydro-wind-PV-thermal power-generation scheduling test systems to verify the feasibility and effectiveness of the LAPO algorithm to solve the STHS problem with the integration of renewable energy sources. The first test system includes four hydro and three thermal units to obtain the optimal solution to the STHS problem without considering the effect of renewable energy sources. The second test 
system contains a multi-chain cascade of four hydropower-generating units, three thermal units, a single wind farm, and a single solar-power-generating unit. The third test system consists of a multi-chain cascade of four hydro and ten thermal-power-generating units. The fourth test system consists of a multi-chain cascade of four hydro, eight thermal-powergenerating units, one equivalent wind farm, and one equivalent PV power-generation unit. Finally, the fifth test system consists of a multi-chain cascade of four hydro units, eight thermal-power-generating units, and two wind-farm generating units. There are two objectives in this system. The first objective function is the operation cost of thermal-power generation with consideration of the valve-loading-point impact, as in (1). Moreover, the total emission caused by thermal units is considered the second objective function. The hydraulic network of these test systems is demonstrated in Figure 3. The entire scheduling period is 1 day that is divided into 24 intervals. The test systems have been explained in detail and the results have been described below.

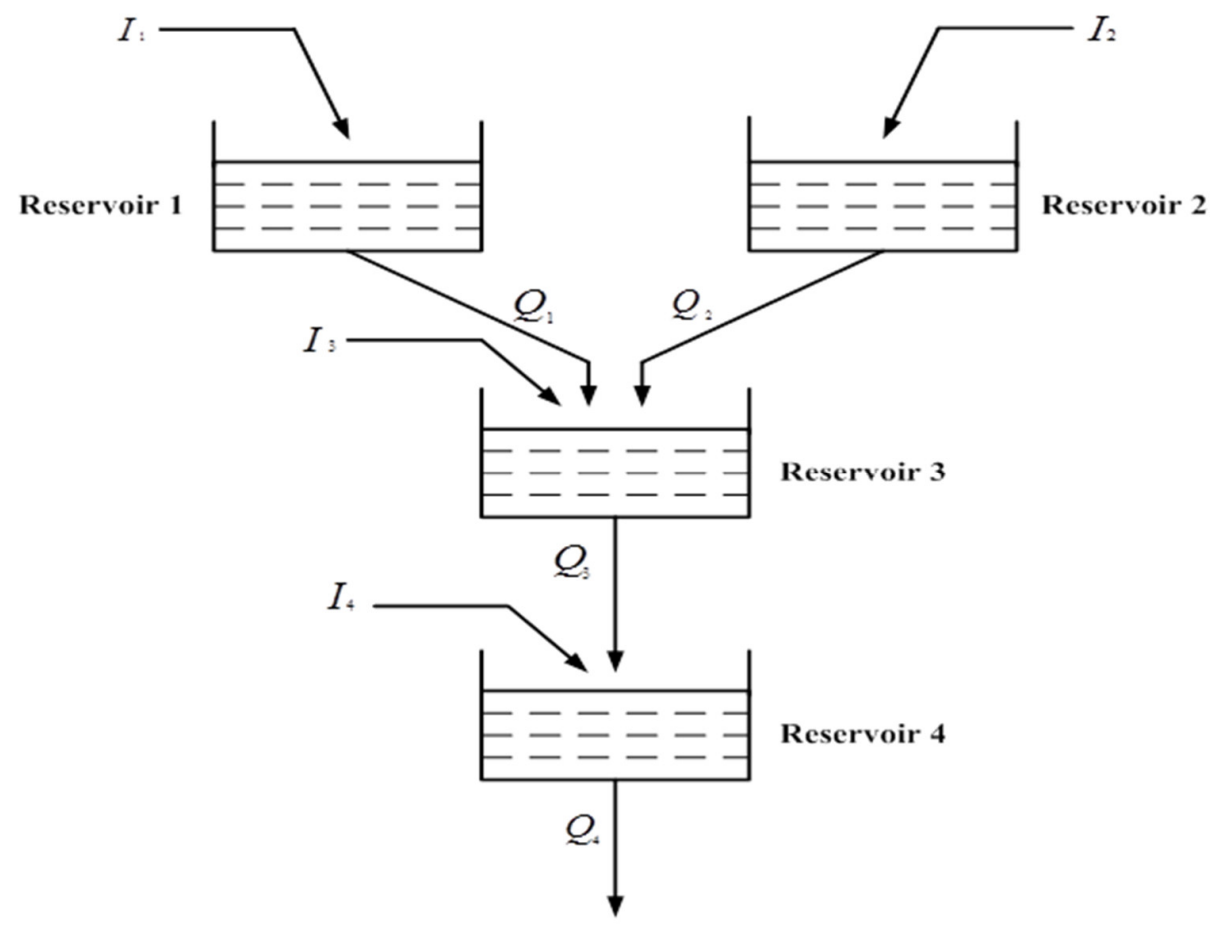

Figure 3. Hydraulic system network.

\subsection{Test System 1}

In this system, the LAPO algorithm can be used to obtain the optimal solution to the STHS problem without considering the effect of renewable energy sources. The valve-point loading impact of thermal-power plants is considered. All data details of the hydrothermal system are adopted from [38], while the emission coefficients of the thermal unit are given in [34]. The LAPO algorithm is optimal to solve the STHS problem by finding the minimum total fuel cost and reducing the emission rate of the thermal units with efficiency. The minimum cost that can be found by the LAPO algorithm is $\$ 38,800.75$. The optimal power generation of the hydro, thermal units, and water discharges of each hour to minimize the fuel cost are shown in Table 3. The optimal results obtained by the LAPO method are compared to heuristic methods in Table 4 . The minimum emission that can be found by LAPO is $17,347.325 \mathrm{Ib}$. The optimal power generation of four hydro units acquired from that LAPO method to minimize the fuel cost is shown in Figure 4. The optimal power generation of four hydro units acquired from the LAPO method to minimize the emission rate is shown in Figure 5. 
Table 3. Optimal power generation of thermal and hydro units and water discharge of hydropower units for Test System 1 to minimize cost.

\begin{tabular}{|c|c|c|c|c|c|c|c|c|c|c|c|c|}
\hline \multirow{2}{*}{ Hours (h) } & \multicolumn{4}{|c|}{ Water Discharge Rates $\left(10^{4} \mathrm{~m}^{3} / \mathrm{s}\right)$} & \multicolumn{4}{|c|}{ Hydro Power (MW) } & \multicolumn{3}{|c|}{ Thermal Power (MW) } & \multirow{2}{*}{$\begin{array}{c}\begin{array}{c}\text { Total Load } \\
\text { (MW) }\end{array} \\
\text { PD }\end{array}$} \\
\hline & Qh1 & Qh2 & Qh3 & Qh4 & Ph1 & Ph2 & Ph3 & Ph4 & Ps1 & Ps2 & Ps3 & \\
\hline 1 & 11.881 & 14.880 & 17.128 & 10.441 & 92.37 & 83.227 & 29.169 & 177.984 & 102.638 & 124.877 & 139.724 & 750 \\
\hline 2 & 5.299 & 6.082 & 22.175 & 17.215 & 55.483 & 46.549 & 4.485 & 216.396 & 102.675 & 124.887 & 229.522 & 780 \\
\hline 3 & 13.802 & 13.592 & 11.488 & 23.312 & 95.463 & 78.521 & 38.674 & 207.574 & 20.012 & 209.757 & 50.007 & 700 \\
\hline 4 & 14.552 & 14.352 & 27.639 & 24.236 & 91.949 & 75.821 & 0 & 199.121 & 102.669 & 40.001 & 139.801 & 650 \\
\hline 5 & 5.8224 & 14.9813 & 25.821 & 15.967 & 56.246 & 72.473 & 0 & 258.852 & 102.664 & 40.0032 & 139.766 & 670 \\
\hline 6 & 14.999 & 13.753 & 10.080 & 24.148 & 87.053 & 70.288 & 38.070 & 325.225 & 99.596 & 40 & 139.778 & 800 \\
\hline 7 & 14.061 & 14.363 & 22.972 & 24.989 & 86.437 & 71.486 & 0 & 327.820 & 20.148 & 124.834 & 319.271 & 950 \\
\hline 8 & 13.674 & 8.094 & 29.754 & 24.582 & 86.147 & 48.528 & 0 & 326.620 & 20.004 & 209.427 & 319.263 & 1010 \\
\hline 9 & 14.951 & 12.124 & 10.746 & 14.313 & 86.628 & 65.992 & 38.504 & 262.311 & 102.671 & 124.897 & 409.013 & 1090 \\
\hline 10 & 12.068 & 14.793 & 22.851 & 16.660 & 83.597 & 72.197 & 0 & 282.772 & 102.626 & 40.000 & 498.795 & 1080 \\
\hline 11 & 10.949 & 12.881 & 29.978 & 22.735 & 81.118 & 68.188 & 0 & 319.873 & 102.653 & 209.805 & 318.360 & 1100 \\
\hline 12 & 12.959 & 14.548 & 12.827 & 23.469 & 85.279 & 71.807 & 43.305 & 322.807 & 102.587 & 294.706 & 229.505 & 1150 \\
\hline 13 & 7.645 & 6.000 & 23.631 & 17.610 & 66.860 & 37.085 & 0 & 290.082 & 102.277 & 294.397 & 319.2940 & 1110 \\
\hline 14 & 12.479 & 12.934 & 10.477 & 23.523 & 86.153 & 68.327 & 38.361 & 323.010 & 154.915 & 40.0035 & 319.270 & 1030 \\
\hline 15 & 5.250 & 10.724 & 10.642 & 23.184 & 51.663 & 61.030 & 38.454 & 321.706 & 102.663 & 294.730 & 139.783 & 1010 \\
\hline 18 & 14.999 & 14.990 & 10.003 & 20.425 & 86.620 & 72.486 & 38.052 & 308.464 & 174.906 & 209.925 & 229.517 & 1120 \\
\hline 19 & 11.788 & 9.4846 & 28.025 & 24.983 & 82.931 & 55.652 & 0 & 327.803 & 164.339 & 209.750 & 229.523 & 1070 \\
\hline 20 & 14.671 & 6.787 & 12.142 & 24.791 & 86.640 & 41.686 & 42.707 & 327.2481 & 102.671 & 40.000 & 409.035 & 1050 \\
\hline 21 & 6.073 & 14.969 & 29.999 & 24.984 & 55.318 & 72.457 & 0 & 327.806 & 20.000 & 294.674 & 139.751 & 910 \\
\hline 22 & 14.999 & 13.959 & 12.685 & 18.017 & 86.620 & 70.717 & 38.253 & 293.043 & 102.663 & 40.007 & 228.700 & 860 \\
\hline 23 & 8.985 & 9.7949 & 10.115 & 22.697 & 72.635 & 57.085 & 38.099 & 319.711 & 102.658 & 209.802 & 50.007 & 850 \\
\hline 24 & 10.875 & 14.999 & 16.860 & 24.925 & 95.751 & 80.948 & 54.837 & 303.378 & 174.997 & 40.096 & 50.000 & 800 \\
\hline
\end{tabular}


Table 4. Comparison of the simulation results for Test System 1.

\begin{tabular}{cccc}
\hline Algorithm & Minimum Cost (\$) & Average Cost (\$) & Maximum Cost (\$) \\
\hline LAPO & $38,800.75$ & $38,915.23$ & 39,520 \\
MDNLPSO [11] & 40,179 & 40,637 & 41,182 \\
CPSO [30] & $40,204.32$ & $40,592.73$ & $40,831.55$ \\
TLPSOS [36] & $40,298.28$ & $40,298.28$ & $40,298.28$ \\
ALO [26] & $40,780.05$ & $41,094.3414$ & $40,905.8259$ \\
ORCCRO [39] & $40,936.65$ & $41,127.6819$ & $40,944.2938$ \\
MCDE [6] & $40,945.75$ & $41,380.54$ & $41,977.04$ \\
ACABC [9] & $41,074.42$ & $\mathrm{NA}$ & $\mathrm{NA}$ \\
RCCRO [39] & $41,497.85$ & $41,502.3669$ & $41,498.2129$ \\
DGSA [40] & $41,751.15$ & $41,989.02$ & $41,821.49$ \\
CSA [41] & $42,244.057$ & $\mathrm{NA}$ & $\mathrm{NA}$ \\
MDE [42] & $42,611.14$ & $\mathrm{NA}$ & $\mathrm{NA}$ \\
PSO [43] & 44,740 & $\mathrm{NA}$ & $\mathrm{NA}$ \\
DE [42] & $44,526.10$ & $\mathrm{NA}$ & $\mathrm{NA}$ \\
EP [34] & $45,063.004$ & $\mathrm{NA}$ & $\mathrm{NA}$ \\
\hline
\end{tabular}

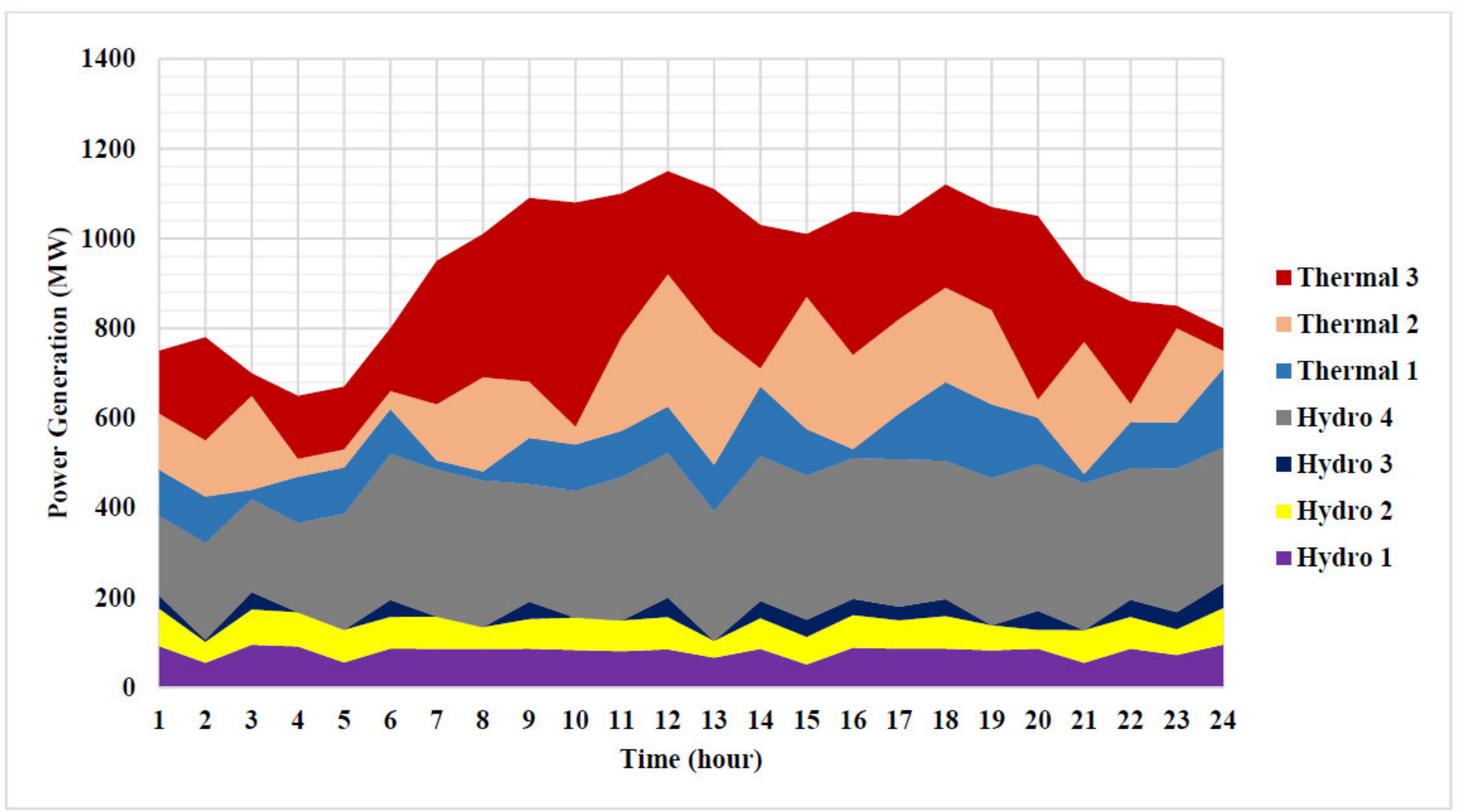

Figure 4. Optimal power generation of thermal and hydro units for Test System 1 to minimize cost.

\subsection{Test System 2}

To analyze the effect of renewable energy sources, this system consists of four hydropower units, three thermal-power units, one equivalent wind-power unit, and one equivalent PV-generating unit, but this system is more complex than Test System 1 due to the constraints of the wind and PV-generating units. The rating of the wind-powergenerating unit is $P_{w r}=150 \mathrm{MW}$. The cut in, cut out, and rated wind speeds are $v_{\text {in }}=4 \mathrm{~m} / \mathrm{s}, v_{o}=25 \mathrm{~m} / \mathrm{s}$, and $v_{r}=15 \mathrm{~m} / \mathrm{s}$, respectively. The cost coefficient for the wind-power-generating unit is $k_{w}=3.25$. The cost coefficient for the PV power-generating unit is $k_{s}=3.5$, The rating of the PV-power-generating unit is $P_{p v r}=150 \mathrm{MW}$. The data details of renewable energy can be found in [28]. With the integration of renewable energy, the total cost obtained by using the LAPO algorithm can be reduced to $\$ 38,210.073$, 
which helps in saving $\$ 590.68 /$ day. The total cost that can be saved in the year is $\$ 215,597$. The optimal power generation for hydro-thermal-wind-PV-generating units and water discharge rate obtained by the LAPO algorithm to minimize the fuel cost is shown in Table 5. The optimal power generation of hydropower-generating units for the provided optimal solution to Test System 2 to minimize the cost is shown in Figure 6. The minimum emission obtained by LAPO is $14,921.908 \mathrm{Ib}$. It is obvious that the emission rate can be reduced to $2425.42 \mathrm{Ib}$ /day by integrating renewable energy. The optimal power generation of hydropower-generating units for the provided optimal solution to Test System 2 to minimize the emission rate is shown in Figure 7.

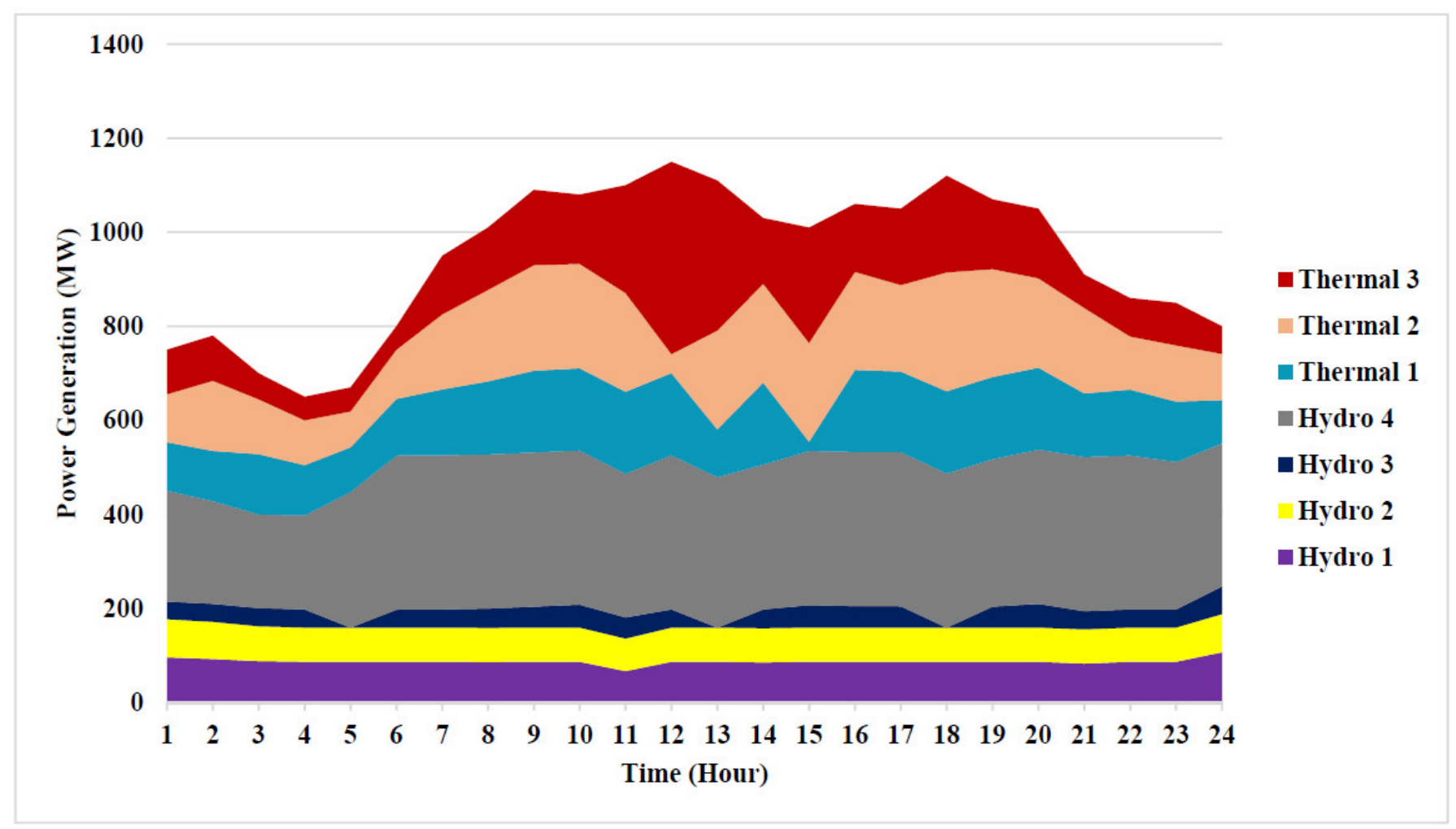

Figure 5. Optimal power generation of thermal and hydro units for Test System 1 to minimize emission.

\subsection{Test System 3}

This system is larger than Test Systems 1 and 2. The hydrothermal system comprises four hydro and ten thermal-power-generating units. The system data are adopted from [43]. The optimal fuel cost that can be achieved by the LAPO algorithm is $\$ 161,746.4$. Tables 6 and 7 show the optimal variables for the given optimal water-discharge-, hydro-, and thermal-power generation. It is clear that the scheduling results that can be found by the LAPO method satisfy all hydraulic and electric system constraints. The simulation results of the LAPO method are compared to different methods in Table 8. Figure 8 shows the optimal power generation of thermal and hydro-generating units for Test System 3 to minimize cost. 
Table 5. Optimal water discharge of hydropower units and optimal power generation of hydro-thermal-wind-PV generating units for Test System 2 to minimize cost.

\begin{tabular}{|c|c|c|c|c|c|c|c|c|c|c|c|c|c|}
\hline \multirow{2}{*}{ Hours (h) } & \multicolumn{4}{|c|}{ Water Discharge Rates $\left(10^{4} \mathrm{~m}^{3} / \mathrm{s}\right)$} & \multicolumn{4}{|c|}{ Hydro Power (MW) } & \multicolumn{3}{|c|}{ Thermal Power (MW) } & \multicolumn{2}{|c|}{ RE (MW) } \\
\hline & Qh1 & Qh2 & Qh3 & Qh4 & Ph1 & Ph2 & Ph3 & Ph4 & Ps1 & Ps2 & Ps3 & $\mathbf{P}_{\mathbf{W}}$ & $\mathbf{P}_{\mathbf{P V}}$ \\
\hline 1 & 9.214 & 11.549 & 17.709 & 14.811 & 82.387 & 76.720 & 32.173 & 213.054 & 102.571 & 124.750 & 50.023 & 68.322 & 0.000 \\
\hline 2 & 8.346 & 13.687 & 11.911 & 18.839 & 77.682 & 78.995 & 38.624 & 216.981 & 102.667 & 125.000 & 139.579 & 0.471 & 0.000 \\
\hline 3 & 14.193 & 13.851 & 12.169 & 24.678 & 95.500 & 75.487 & 38.541 & 199.442 & 20.039 & 124.891 & 50.611 & 95.489 & 0.000 \\
\hline 4 & 14.220 & 12.885 & 14.895 & 16.886 & 91.504 & 69.912 & 35.216 & 176.028 & 102.677 & 124.414 & 50.187 & 0.062 & 0.000 \\
\hline 5 & 13.870 & 14.851 & 10.651 & 16.432 & 86.411 & 72.285 & 40.201 & 239.963 & 21.040 & 40.048 & 139.760 & 30.292 & 0.000 \\
\hline 6 & 14.899 & 14.466 & 14.094 & 20.989 & 86.636 & 71.666 & 36.656 & 311.552 & 20.139 & 125.324 & 139.808 & 8.219 & 0.000 \\
\hline 7 & 12.497 & 14.848 & 12.257 & 21.012 & 84.489 & 72.280 & 40.319 & 311.675 & 102.908 & 124.833 & 139.044 & 55.117 & 19.335 \\
\hline 8 & 13.760 & 14.968 & 27.689 & 24.915 & 86.222 & 72.455 & 0.000 & 327.607 & 101.950 & 209.887 & 141.301 & 24.918 & 45.660 \\
\hline 9 & 14.102 & 13.266 & 12.985 & 24.794 & 86.461 & 69.171 & 38.014 & 327.257 & 102.080 & 209.225 & 139.617 & 51.327 & 66.849 \\
\hline 10 & 14.698 & 11.287 & 12.181 & 24.731 & 86.642 & 63.165 & 38.536 & 327.070 & 102.492 & 209.928 & 139.937 & 34.530 & 77.700 \\
\hline 11 & 5.568 & 14.985 & 11.813 & 24.755 & 53.512 & 72.479 & 38.646 & 327.140 & 103.595 & 40.865 & 319.245 & 47.760 & 96.758 \\
\hline 12 & 9.268 & 11.928 & 24.017 & 24.962 & 77.378 & 65.369 & 0.000 & 327.743 & 102.440 & 124.195 & 319.332 & 33.382 & 100.160 \\
\hline 13 & 13.923 & 9.859 & 24.269 & 22.203 & 89.011 & 57.372 & 0.000 & 317.535 & 102.291 & 208.071 & 228.475 & 0.699 & 106.545 \\
\hline 14 & 14.015 & 8.542 & 13.182 & 24.768 & 87.832 & 51.307 & 38.563 & 327.178 & 102.924 & 209.795 & 50.003 & 50.578 & 111.820 \\
\hline 15 & 12.347 & 14.105 & 14.311 & 24.698 & 84.717 & 71.007 & 42.464 & 326.969 & 102.577 & 210.031 & 50.059 & 40.255 & 81.921 \\
\hline 16 & 14.169 & 14.878 & 12.355 & 24.979 & 86.496 & 72.325 & 46.364 & 327.792 & 102.600 & 124.843 & 140.478 & 128.744 & 30.358 \\
\hline 19 & 14.358 & 13.659 & 10.378 & 23.671 & 86.575 & 70.083 & 50.714 & 314.179 & 20.040 & 293.928 & 229.887 & 4.596 & 0.000 \\
\hline 20 & 10.979 & 11.158 & 14.787 & 17.918 & 80.634 & 62.695 & 50.447 & 285.915 & 102.682 & 124.674 & 318.791 & 24.162 & 0.000 \\
\hline 21 & 10.802 & 12.270 & 29.105 & 22.065 & 80.059 & 66.442 & 0.000 & 306.975 & 101.140 & 124.853 & 230.298 & 0.233 & 0.000 \\
\hline 22 & 14.492 & 13.813 & 18.592 & 20.909 & 86.613 & 70.416 & 23.588 & 311.124 & 101.058 & 125.484 & 138.634 & 3.084 & 0.000 \\
\hline 23 & 13.513 & 14.921 & 28.134 & 22.546 & 85.989 & 72.388 & 0.000 & 309.510 & 102.278 & 125.034 & 139.843 & 14.959 & 0.000 \\
\hline 24 & 7.005 & 11.643 & 10.194 & 24.448 & 72.180 & 72.364 & 56.414 & 302.196 & 102.296 & 40.040 & 139.651 & 14.859 & 0.000 \\
\hline \multicolumn{14}{|c|}{ Total cost $=\$ 38,210.073$} \\
\hline
\end{tabular}




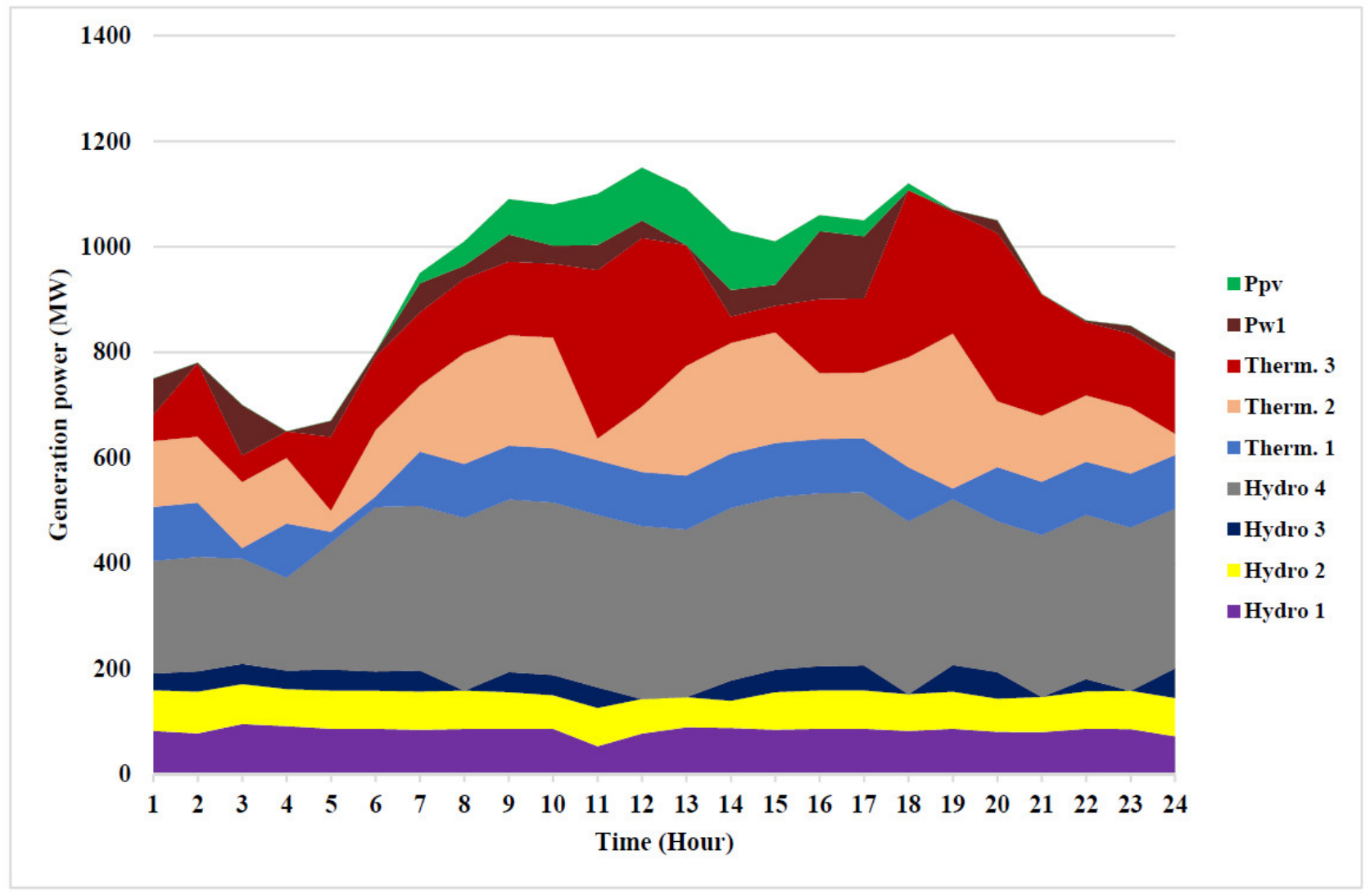

Figure 6. Optimal power generation of thermal and hydro units for Test System 2 to minimize cost.

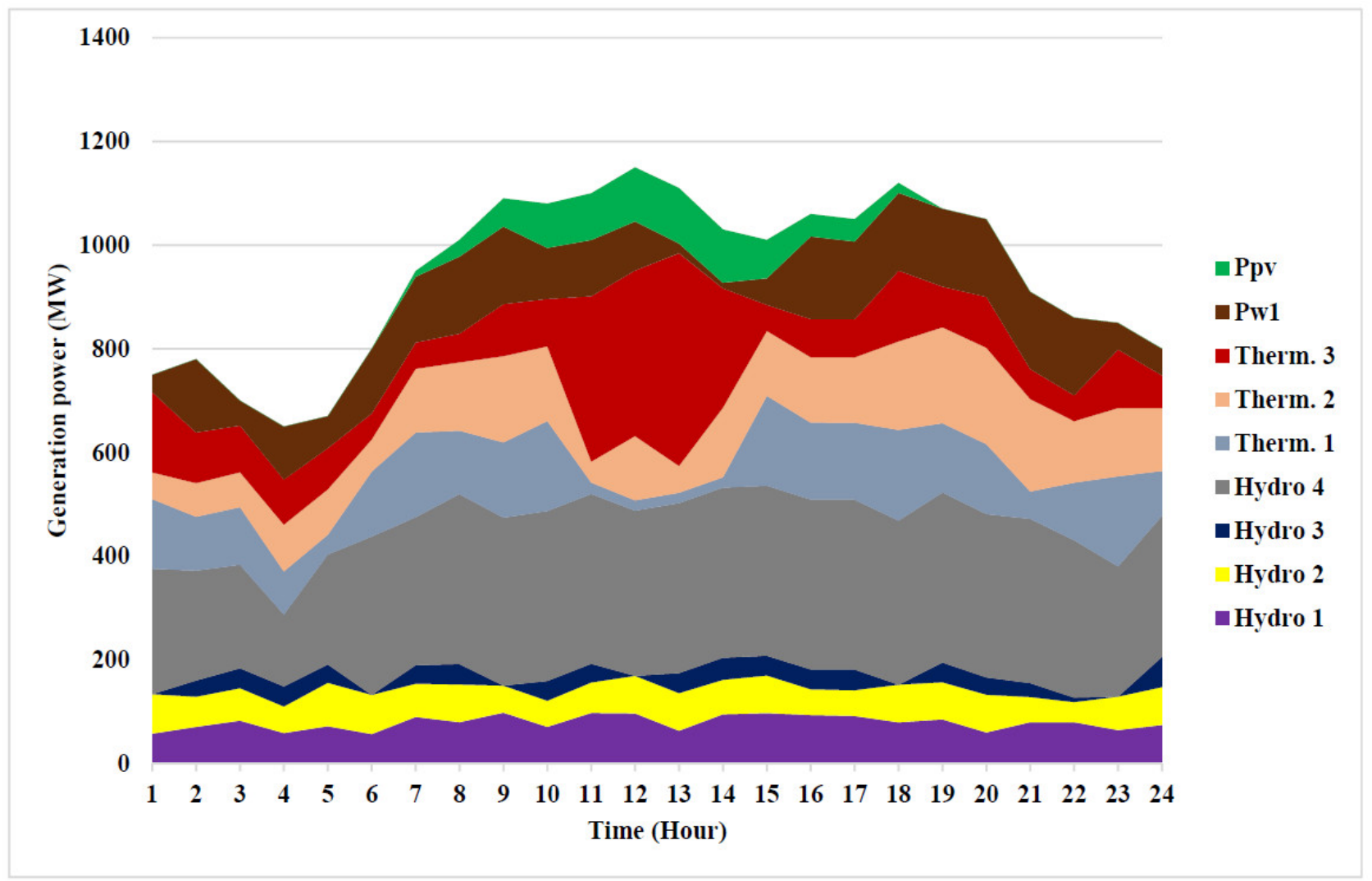

Figure 7. Optimal power generation of thermal and hydro units for Test System 2 to minimize emission. 
Table 6. Optimal power generation and water discharge of hydropower units for Test System 3.

\begin{tabular}{|c|c|c|c|c|c|c|c|c|}
\hline \multirow{2}{*}{ Hours (h) } & \multicolumn{4}{|c|}{ Water Discharge Rates $\left(10^{4} \mathrm{~m}^{3} / \mathrm{s}\right)$} & \multicolumn{4}{|c|}{ Hydro Power (MW) } \\
\hline & Qh1 & Qh2 & Qh3 & Qh4 & Ph1 & Ph2 & Ph3 & Ph4 \\
\hline 1 & 6.760 & 12.010 & 12.396 & 22.714 & 67.493 & 78.042 & 41.173 & 243.511 \\
\hline 2 & 5.446 & 13.840 & 19.180 & 19.813 & 57.668 & 78.867 & 20.980 & 208.461 \\
\hline 3 & 10.334 & 13.490 & 11.538 & 24.814 & 89.058 & 74.456 & 38.675 & 199.517 \\
\hline 4 & 7.351 & 14.801 & 15.407 & 24.734 & 71.952 & 72.209 & 34.096 & 199.474 \\
\hline 5 & 8.261 & 9.964 & 15.398 & 18.032 & 77.287 & 57.842 & 34.118 & 253.373 \\
\hline 6 & 8.672 & 11.778 & 17.941 & 24.901 & 79.209 & 64.875 & 26.228 & 298.063 \\
\hline 7 & 6.503 & 12.264 & 10.376 & 17.186 & 65.189 & 66.423 & 38.296 & 286.888 \\
\hline 8 & 8.208 & 14.965 & 12.397 & 24.995 & 77.135 & 72.450 & 38.434 & 327.835 \\
\hline 9 & 11.174 & 8.820 & 12.778 & 21.182 & 91.325 & 52.392 & 38.185 & 312.563 \\
\hline 10 & 13.096 & 14.794 & 12.438 & 24.982 & 95.848 & 72.199 & 38.411 & 327.800 \\
\hline 11 & 12.535 & 14.764 & 11.850 & 24.920 & 94.370 & 72.152 & 44.236 & 327.621 \\
\hline 12 & 7.391 & 10.933 & 13.414 & 22.485 & 71.490 & 61.845 & 37.576 & 318.797 \\
\hline 13 & 9.678 & 12.937 & 11.354 & 24.851 & 85.353 & 68.334 & 42.941 & 327.424 \\
\hline 14 & 6.230 & 13.024 & 14.458 & 24.132 & 64.456 & 68.563 & 39.095 & 325.170 \\
\hline 15 & 11.994 & 11.273 & 10.280 & 24.888 & 96.367 & 63.117 & 38.229 & 312.290 \\
\hline 16 & 8.689 & 14.972 & 29.838 & 24.968 & 81.714 & 72.461 & 0.000 & 327.758 \\
\hline 17 & 13.171 & 12.519 & 22.438 & 24.287 & 98.328 & 67.179 & 2.786 & 320.525 \\
\hline 18 & 10.784 & 9.906 & 12.669 & 24.989 & 89.995 & 57.582 & 38.265 & 327.789 \\
\hline 19 & 10.022 & 14.670 & 11.550 & 24.924 & 85.627 & 72.005 & 38.674 & 327.634 \\
\hline 20 & 6.862 & 6.643 & 19.986 & 23.930 & 66.834 & 40.874 & 17.696 & 324.478 \\
\hline 21 & 9.640 & 9.382 & 10.295 & 17.871 & 82.517 & 55.943 & 38.240 & 291.995 \\
\hline 22 & 9.895 & 14.454 & 12.722 & 23.527 & 82.935 & 71.647 & 38.227 & 323.023 \\
\hline 23 & 12.989 & 14.809 & 17.387 & 24.938 & 90.712 & 72.221 & 28.280 & 327.675 \\
\hline 24 & 11.357 & 13.412 & 24.417 & 24.699 & 97.803 & 77.733 & 20.806 & 302.835 \\
\hline
\end{tabular}

\subsection{Test System 4}

Test System 4 is similar to Test System 3, but two thermal-power-generating units are replaced by wind and PV power units. The optimal cost obtained by the LAPO method to solve the STHS problem with wind and PV power integration system is $\$ 158,572.8$. The value of fuel cost that is saved by integrating renewable energy is $\$ 3173.6 /$ day. In other words, the total annual saving is $\$ 1,158,364$. The data for renewable energy are similar to Test System 2. The optimal hydropower generation and water discharge are presented in Table 9. The thermal-power generation, wind, and PV-power units for this test system are listed in Table 10. Hourly hydro- and thermal-power generation of the optimal solution for Test System 4 is shown in Figure 9. 
Table 7. Optimal thermal generation for Test System 3.

\begin{tabular}{|c|c|c|c|c|c|c|c|c|c|c|}
\hline \multirow{2}{*}{$\begin{array}{l}\text { Hours } \\
\text { (h) }\end{array}$} & \multicolumn{10}{|c|}{ Thermal Power (MW) } \\
\hline & Ps1 & Ps2 & Ps3 & Ps4 & Ps5 & Ps6 & Ps7 & Ps8 & Ps9 & Ps10 \\
\hline 1 & 319.329 & 199.965 & 94.364 & 69.818 & 124.796 & 189.692 & 163.440 & 35.028 & 97.976 & 25.372 \\
\hline 2 & 139.517 & 274.234 & 94.918 & 69.222 & 124.509 & 239.416 & 163.417 & 35.178 & 97.002 & 176.611 \\
\hline 3 & 139.796 & 274.419 & 20.186 & 70.102 & 274.449 & 139.641 & 104.040 & 35.776 & 99.753 & 140.134 \\
\hline 4 & 229.711 & 348.804 & 97.751 & 20.379 & 74.830 & 139.648 & 103.858 & 35.280 & 97.494 & 124.515 \\
\hline 5 & 229.529 & 272.246 & 93.673 & 69.654 & 74.655 & 138.513 & 163.450 & 35.160 & 96.971 & 73.529 \\
\hline 6 & 229.672 & 50.164 & 94.925 & 119.624 & 174.692 & 239.511 & 104.444 & 35.055 & 106.832 & 176.706 \\
\hline 7 & 319.227 & 274.170 & 93.270 & 69.887 & 124.561 & 139.562 & 162.999 & 35.113 & 98.052 & 176.350 \\
\hline 8 & 319.290 & 54.043 & 96.594 & 74.199 & 174.471 & 289.433 & 223.111 & 35.412 & 98.156 & 129.437 \\
\hline 9 & 229.428 & 124.793 & 94.384 & 119.194 & 274.256 & 339.054 & 103.626 & 35.125 & 98.252 & 177.423 \\
\hline 10 & 319.774 & 274.655 & 96.785 & 69.947 & 275.943 & 189.591 & 45.030 & 35.188 & 159.733 & 79.095 \\
\hline 11 & 320.048 & 125.074 & 95.298 & 120.330 & 224.733 & 190.024 & 163.817 & 35.057 & 109.062 & 178.176 \\
\hline 12 & 409.140 & 274.323 & 20.044 & 119.761 & 174.385 & 239.579 & 103.397 & 35.210 & 158.384 & 126.070 \\
\hline 13 & 229.535 & 124.644 & 95.479 & 119.631 & 323.491 & 289.222 & 163.452 & 35.028 & 25.489 & 179.978 \\
\hline 14 & 229.384 & 274.084 & 89.611 & 119.352 & 224.457 & 174.504 & 163.176 & 35.168 & 97.131 & 125.850 \\
\hline 15 & 409.015 & 199.616 & 95.678 & 51.038 & 273.530 & 239.439 & 45.090 & 35.136 & 25.152 & 126.305 \\
\hline 16 & 319.914 & 199.477 & 95.586 & 119.724 & 224.602 & 189.559 & 163.545 & 35.197 & 103.567 & 126.894 \\
\hline 17 & 139.667 & 421.838 & 94.528 & 69.850 & 174.330 & 239.204 & 163.314 & 35.054 & 97.669 & 125.727 \\
\hline 18 & 318.913 & 424.026 & 94.116 & 69.549 & 274.606 & 139.759 & 104.756 & 35.200 & 98.136 & 47.307 \\
\hline 19 & 139.699 & 274.526 & 20.807 & 122.996 & 324.556 & 189.534 & 163.479 & 35.001 & 98.366 & 177.097 \\
\hline 20 & 139.766 & 349.273 & 103.877 & 69.888 & 372.111 & 89.593 & 104.221 & 35.029 & 160.000 & 176.360 \\
\hline 21 & 229.409 & 274.535 & 20.314 & 69.546 & 224.309 & 189.571 & 163.589 & 35.073 & 159.362 & 75.598 \\
\hline 22 & 229.553 & 273.538 & 94.161 & 20.283 & 224.512 & 139.818 & 103.896 & 35.057 & 97.956 & 125.394 \\
\hline 23 & 139.979 & 124.657 & 125.709 & 69.682 & 323.970 & 189.614 & 45.162 & 35.250 & 99.308 & 177.770 \\
\hline 24 & 408.281 & 124.712 & 20.438 & 20.042 & 124.704 & 239.473 & 104.203 & 35.046 & 97.895 & 125.940 \\
\hline
\end{tabular}

Table 8. Comparison of simulation results for Test System 3.

\begin{tabular}{cccc}
\hline Algorithm & Minimum Cost (\$) & Average Cost (\$) & Maximum Cost (\$) \\
\hline LAPO & $161,746.4$ & $160,445.4$ & $161,935.4$ \\
ORCCRO [39] & $163,066.0337$ & $163,068.7739$ & $163,134.5391$ \\
RCCRO [39] & $164,138.6517$ & $164,140.3997$ & $164,182.3520$ \\
SPPSO [44] & $167,710.56$ & $168,688.92$ & $170,879.30$ \\
SPSO [44] & $189,350.63$ & $190,560.31$ & $191,844.28$ \\
MDE [44] & $177,338.60$ & $179,676.35$ & $182,172.01$ \\
DE [44] & $170,964.15$ & NA & NA \\
MCDE [6] & $165,331.7$ & $166,116.4$ & $167,060.6$ \\
IDE [29] & $170,576.5$ & $170,589.6$ & $170,608.3$ \\
\hline
\end{tabular}

\subsection{Test System 5}

Test System 5 is similar to Test System 3, but two thermal-power-generating units are replaced by two wind-power-generating units. The optimal cost of Test System 5, which is obtained by LAPO method is $\$ 158,342.4$, which is reduced to $\$ 3404$ /day when compared to Test System 3 by utilizing renewable energy sources. The total annual saving is $\$ 1,242,460$. The hourly water discharge of hydro units and hydropower generation are illustrated in Table 11. The optimal solution to thermal, wind, and PV units are listed in Table 12. Figure 10 shows the optimal power generation of thermal and hydro units for Test System 5 to minimize cost. 


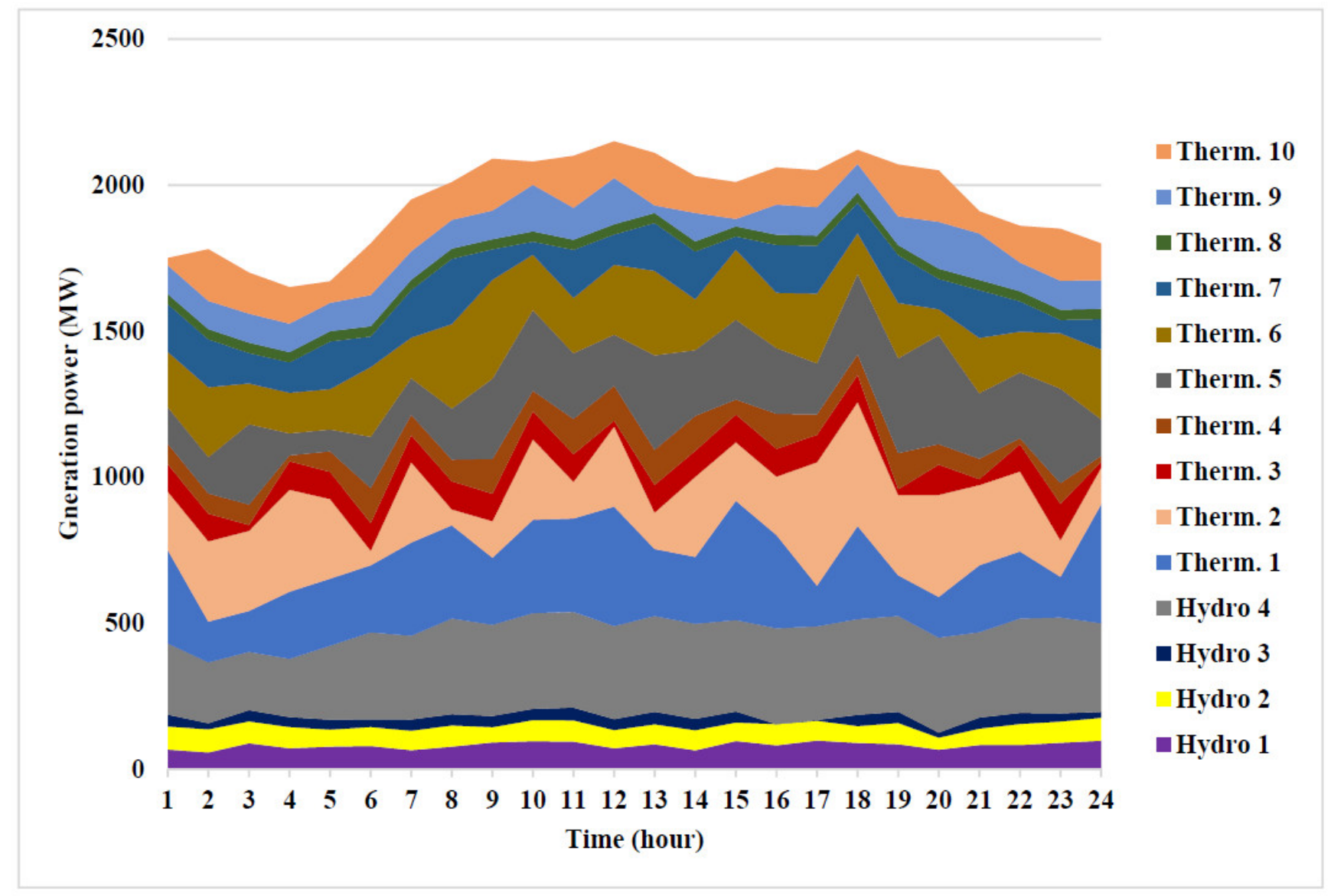

Figure 8. Optimal power generation of thermal and hydro units for Test System 3 to minimize cost.

Table 9. Optimal power generation and water discharge of hydropower units for Test System 4.

\begin{tabular}{|c|c|c|c|c|c|c|c|c|}
\hline \multirow{2}{*}{ Hours (h) } & \multicolumn{4}{|c|}{ Water Discharge Rates $\left(10^{4} \mathrm{~m}^{3} / \mathrm{s}\right)$} & \multicolumn{4}{|c|}{ Hydro Power (MW) } \\
\hline & Qh1 & Qh2 & Qh3 & Qh4 & Ph1 & Ph2 & Ph3 & $\mathrm{Ph} 4$ \\
\hline 1 & 7.925 & 11.136 & 15.490 & 17.354 & 75.249 & 75.421 & 47.159 & 227.490 \\
\hline 2 & 5.078 & 8.343 & 14.311 & 21.083 & 54.305 & 61.768 & 36.305 & 219.114 \\
\hline 3 & 10.601 & 14.585 & 12.904 & 23.173 & 89.848 & 80.999 & 38.084 & 197.853 \\
\hline 4 & 5.035 & 14.937 & 10.163 & 23.248 & 53.819 & 76.729 & 38.139 & 197.966 \\
\hline 5 & 9.371 & 12.213 & 14.935 & 20.424 & 83.602 & 66.927 & 35.134 & 227.198 \\
\hline 6 & 7.893 & 14.849 & 17.662 & 18.952 & 74.767 & 72.282 & 27.285 & 288.448 \\
\hline 7 & 7.700 & 12.670 & 19.807 & 24.977 & 73.598 & 67.610 & 17.971 & 327.784 \\
\hline 8 & 7.617 & 14.965 & 12.444 & 24.949 & 73.424 & 72.450 & 38.407 & 327.706 \\
\hline 9 & 9.724 & 9.908 & 11.767 & 24.971 & 85.735 & 57.592 & 38.654 & 327.768 \\
\hline 10 & 7.420 & 11.803 & 15.315 & 15.756 & 73.029 & 64.957 & 34.309 & 275.292 \\
\hline 11 & 11.805 & 12.253 & 13.303 & 21.505 & 95.566 & 66.390 & 37.699 & 314.207 \\
\hline 12 & 12.573 & 14.425 & 10.641 & 24.884 & 96.840 & 71.595 & 38.454 & 327.518 \\
\hline 13 & 5.281 & 13.149 & 10.977 & 23.574 & 56.699 & 68.882 & 38.593 & 323.198 \\
\hline 14 & 10.655 & 13.712 & 11.106 & 24.824 & 92.592 & 70.199 & 38.628 & 327.344 \\
\hline 15 & 7.839 & 14.589 & 12.495 & 24.839 & 77.490 & 71.875 & 38.378 & 327.389 \\
\hline 16 & 12.480 & 12.249 & 14.955 & 24.290 & 99.433 & 66.379 & 35.094 & 325.690 \\
\hline 17 & 10.413 & 11.508 & 10.692 & 24.870 & 91.299 & 63.953 & 38.479 & 327.478 \\
\hline 18 & 9.809 & 11.459 & 12.541 & 24.985 & 87.891 & 63.780 & 38.350 & 327.809 \\
\hline 19 & 11.788 & 14.915 & 12.980 & 24.958 & 94.466 & 72.379 & 38.018 & 327.731 \\
\hline 20 & 12.334 & 14.378 & 11.587 & 23.847 & 93.418 & 71.513 & 38.825 & 324.188 \\
\hline 21 & 6.813 & 14.810 & 15.299 & 22.369 & 66.486 & 72.223 & 34.345 & 318.285 \\
\hline 22 & 10.775 & 12.098 & 13.103 & 17.363 & 87.322 & 65.910 & 44.132 & 288.231 \\
\hline 23 & 12.974 & 14.599 & 12.428 & 24.829 & 91.633 & 71.891 & 47.674 & 327.360 \\
\hline 24 & 13.248 & 13.390 & 22.845 & 24.330 & 103.979 & 77.677 & 30.710 & 301.884 \\
\hline
\end{tabular}


Table 10. Optimal power generation of thermal, wind, and PV power generation for Test System 4.

\begin{tabular}{|c|c|c|c|c|c|c|c|c|c|c|}
\hline \multirow{2}{*}{$\begin{array}{c}\text { Hours } \\
\text { (h) }\end{array}$} & \multicolumn{8}{|c|}{ Thermal Power (MW) } & \multicolumn{2}{|c|}{ RE (MW) } \\
\hline & Ps1 & Ps2 & Ps3 & Ps4 & Ps5 & Ps6 & Ps7 & Ps8 & $\mathbf{P}_{\mathbf{W}}$ & $\mathbf{P}_{\mathbf{P V}}$ \\
\hline 1 & 318.954 & 124.729 & 20.295 & 119.772 & 224.470 & 189.373 & 163.447 & 35.046 & 128.594 & 0.000 \\
\hline 2 & 319.204 & 199.490 & 94.699 & 119.729 & 274.595 & 189.569 & 104.305 & 35.018 & 71.901 & 0.000 \\
\hline 3 & 409.050 & 199.469 & 94.804 & 119.806 & 124.718 & 89.731 & 163.589 & 35.039 & 57.009 & 0.000 \\
\hline 4 & 318.863 & 274.326 & 94.814 & 69.773 & 174.555 & 89.699 & 163.398 & 35.030 & 62.889 & 0.000 \\
\hline 5 & 139.716 & 274.361 & 94.885 & 119.779 & 124.720 & 289.084 & 163.466 & 35.030 & 16.097 & 0.000 \\
\hline 6 & 229.527 & 349.173 & 94.792 & 20.002 & 224.382 & 139.288 & 104.094 & 35.211 & 140.749 & 0.000 \\
\hline 7 & 229.463 & 274.415 & 94.673 & 119.744 & 274.411 & 239.455 & 104.165 & 35.050 & 74.084 & 17.578 \\
\hline 8 & 319.457 & 124.946 & 94.690 & 119.736 & 324.078 & 139.814 & 222.600 & 35.001 & 68.185 & 49.506 \\
\hline 9 & 408.844 & 199.612 & 94.827 & 69.784 & 174.546 & 239.541 & 163.433 & 35.007 & 139.598 & 55.060 \\
\hline 10 & 227.804 & 349.206 & 94.654 & 69.714 & 224.281 & 239.431 & 163.565 & 35.096 & 141.773 & 86.892 \\
\hline 11 & 319.096 & 348.906 & 91.073 & 119.106 & 224.369 & 89.717 & 163.312 & 35.053 & 117.605 & 77.900 \\
\hline 12 & 139.747 & 348.787 & 20.258 & 69.993 & 174.635 & 239.439 & 281.758 & 35.280 & 201.329 & 104.366 \\
\hline 13 & 319.311 & 199.617 & 94.858 & 70.001 & 324.266 & 239.510 & 163.518 & 35.198 & 73.874 & 102.474 \\
\hline 14 & 319.276 & 273.995 & 94.863 & 119.828 & 74.873 & 239.589 & 104.270 & 65.497 & 100.768 & 108.276 \\
\hline 15 & 229.371 & 199.615 & 94.800 & 69.740 & 224.442 & 239.345 & 163.326 & 81.612 & 92.618 & 100.000 \\
\hline 16 & 139.556 & 348.993 & 94.357 & 69.838 & 374.046 & 189.469 & 211.563 & 35.222 & 0.359 & 70.000 \\
\hline 17 & 229.473 & 199.584 & 20.049 & 119.624 & 323.928 & 238.441 & 162.997 & 35.007 & 149.688 & 50.000 \\
\hline 18 & 319.281 & 349.163 & 20.012 & 69.952 & 323.873 & 189.469 & 163.467 & 35.010 & 111.943 & 20.000 \\
\hline 19 & 229.989 & 275.560 & 94.824 & 119.889 & 224.421 & 139.663 & 222.982 & 35.115 & 194.962 & 0.000 \\
\hline 20 & 139.536 & 349.005 & 94.735 & 119.753 & 373.954 & 188.513 & 104.283 & 35.036 & 117.229 & 0.000 \\
\hline 21 & 139.913 & 349.328 & 94.877 & 69.823 & 174.495 & 239.085 & 281.896 & 35.002 & 34.240 & 0.000 \\
\hline 22 & 229.447 & 274.283 & 94.236 & 69.878 & 224.328 & 338.203 & 104.277 & 35.295 & 4.457 & 0.000 \\
\hline 23 & 140.274 & 199.654 & 94.907 & 70.537 & 274.360 & 289.342 & 104.221 & 35.010 & 103.137 & 0.000 \\
\hline 24 & 229.062 & 124.378 & 94.552 & 119.675 & 224.191 & 89.683 & 222.729 & 35.001 & 146.479 & 0.000 \\
\hline
\end{tabular}

\section{0}

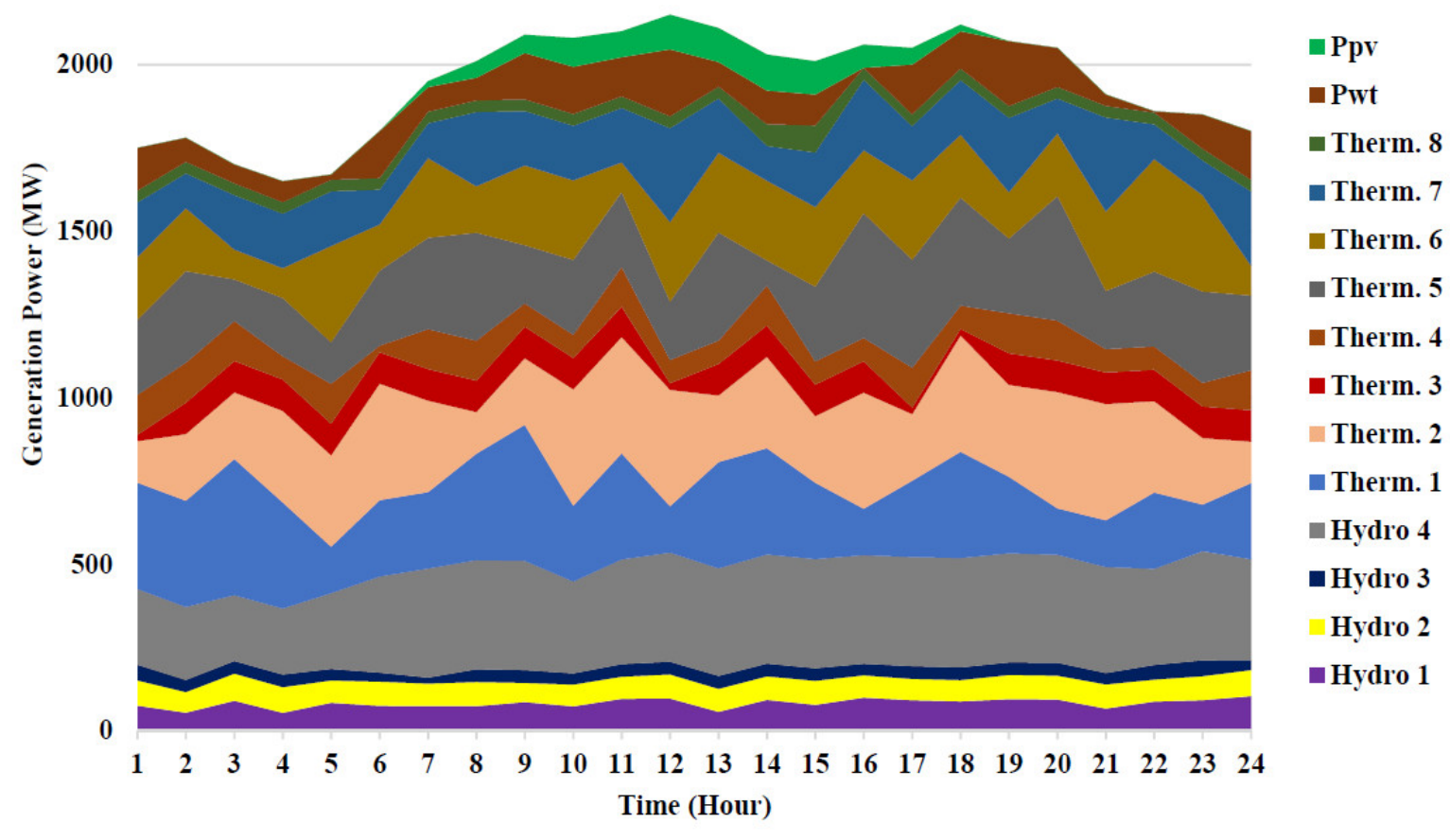

Figure 9. Optimal power generation of thermal and hydro units for Test System 4 to minimize cost. 
Table 11. Optimal water discharge and power generation of hydropower units for test system5.

\begin{tabular}{|c|c|c|c|c|c|c|c|c|}
\hline \multirow{2}{*}{ Hours (h) } & \multicolumn{4}{|c|}{ Water Discharge Rates $\left(10^{4} \mathrm{~m}^{3} / \mathrm{s}\right)$} & \multicolumn{4}{|c|}{ Hydro Power (MW) } \\
\hline & Qh1 & Qh2 & Qh3 & Qh4 & Ph1 & Ph2 & Ph3 & Ph4 \\
\hline 1 & 13.316 & 7.132 & 11.064 & 22.027 & 95.066 & 57.177 & 41.893 & 242.550 \\
\hline 2 & 7.040 & 12.185 & 28.964 & 24.946 & 68.327 & 79.129 & 0.000 & 213.308 \\
\hline 3 & 12.744 & 11.740 & 13.309 & 18.662 & 92.605 & 75.627 & 37.694 & 184.675 \\
\hline 4 & 7.893 & 14.223 & 11.299 & 21.508 & 72.162 & 78.542 & 38.663 & 194.459 \\
\hline 5 & 9.245 & 12.197 & 13.519 & 24.784 & 78.394 & 69.949 & 38.921 & 268.703 \\
\hline 6 & 5.009 & 13.766 & 12.985 & 24.913 & 50.562 & 70.315 & 42.524 & 327.603 \\
\hline 7 & 8.443 & 14.087 & 11.702 & 24.675 & 74.779 & 70.971 & 38.663 & 316.807 \\
\hline 8 & 6.605 & 11.315 & 10.069 & 24.565 & 63.751 & 63.267 & 38.061 & 326.566 \\
\hline 9 & 11.825 & 14.696 & 10.162 & 24.809 & 89.352 & 72.046 & 38.138 & 326.801 \\
\hline 10 & 7.516 & 9.069 & 12.159 & 24.439 & 70.567 & 53.646 & 38.545 & 315.488 \\
\hline 11 & 12.529 & 8.077 & 27.485 & 24.431 & 92.583 & 49.146 & 0.000 & 326.146 \\
\hline 12 & 11.663 & 14.945 & 11.957 & 24.967 & 89.493 & 72.422 & 38.612 & 327.758 \\
\hline 13 & 5.014 & 12.388 & 19.548 & 22.084 & 52.444 & 66.798 & 19.242 & 316.991 \\
\hline 14 & 14.496 & 12.684 & 10.880 & 24.986 & 96.493 & 67.650 & 38.560 & 327.810 \\
\hline 15 & 7.929 & 8.042 & 10.029 & 24.885 & 74.595 & 48.980 & 38.026 & 327.522 \\
\hline 16 & 13.486 & 14.917 & 11.407 & 24.948 & 95.129 & 72.381 & 38.672 & 327.704 \\
\hline 17 & 13.720 & 8.489 & 15.930 & 23.143 & 93.003 & 50.665 & 32.787 & 321.546 \\
\hline 18 & 9.791 & 8.562 & 11.804 & 24.508 & 80.948 & 51.054 & 38.647 & 326.388 \\
\hline 19 & 5.540 & 14.547 & 11.370 & 24.852 & 54.812 & 71.805 & 38.670 & 327.425 \\
\hline 20 & 9.321 & 11.304 & 27.960 & 24.982 & 77.946 & 63.228 & 0.000 & 327.798 \\
\hline 21 & 14.980 & 13.563 & 14.761 & 18.274 & 86.624 & 69.868 & 35.484 & 294.858 \\
\hline 22 & 8.133 & 14.743 & 15.343 & 24.659 & 68.189 & 72.121 & 34.245 & 326.854 \\
\hline 23 & 13.571 & 14.905 & 12.201 & 24.985 & 86.048 & 72.364 & 38.527 & 327.807 \\
\hline 24 & 10.661 & 8.840 & 13.440 & 23.732 & 94.775 & 60.017 & 58.977 & 300.161 \\
\hline
\end{tabular}

Table 12. Optimal power generation of thermal, wind, and PV power generation for Test System 5.

\begin{tabular}{|c|c|c|c|c|c|c|c|c|c|c|}
\hline \multirow{2}{*}{$\begin{array}{l}\text { Hours } \\
\text { (h) }\end{array}$} & \multicolumn{8}{|c|}{ Thermal Power (MW) } & \multicolumn{2}{|c|}{ RE (MW) } \\
\hline & Ps1 & Ps2 & Ps3 & Ps4 & Ps5 & Ps6 & Ps7 & Ps8 & Pw1 & Pw2 \\
\hline 1 & 229.470 & 200.541 & 94.834 & 69.932 & 124.742 & 89.819 & 163.333 & 40.792 & 149.957 & 149.893 \\
\hline 2 & 229.372 & 424.056 & 94.811 & 69.837 & 224.497 & 89.886 & 104.258 & 35.106 & 114.686 & 32.727 \\
\hline 3 & 229.408 & 274.023 & 94.608 & 69.772 & 125.020 & 140.117 & 104.394 & 35.091 & 117.125 & 119.842 \\
\hline 4 & 229.556 & 199.458 & 94.795 & 70.084 & 124.289 & 139.960 & 163.541 & 35.001 & 120.003 & 89.516 \\
\hline 5 & 229.573 & 124.768 & 94.967 & 20.454 & 174.602 & 89.435 & 163.262 & 35.319 & 138.316 & 143.336 \\
\hline 6 & 50.013 & 423.522 & 94.707 & 119.846 & 25.694 & 139.591 & 163.490 & 35.107 & 148.381 & 108.650 \\
\hline 7 & 139.689 & 348.771 & 94.750 & 20.077 & 373.974 & 139.828 & 163.447 & 35.406 & 16.111 & 116.728 \\
\hline 8 & 319.273 & 124.802 & 20.187 & 69.665 & 373.877 & 139.759 & 222.815 & 35.842 & 78.357 & 133.777 \\
\hline 9 & 139.862 & 124.489 & 129.846 & 119.580 & 224.469 & 338.231 & 163.540 & 35.338 & 149.816 & 138.490 \\
\hline 10 & 229.500 & 348.828 & 94.542 & 20.257 & 324.220 & 189.585 & 163.835 & 35.098 & 100.698 & 95.192 \\
\hline 11 & 319.215 & 274.427 & 94.590 & 119.622 & 124.736 & 239.498 & 163.479 & 35.000 & 129.460 & 132.100 \\
\hline 12 & 408.940 & 125.014 & 94.794 & 20.024 & 324.234 & 89.837 & 282.152 & 35.000 & 148.813 & 92.900 \\
\hline 13 & 409.009 & 349.392 & 20.119 & 119.363 & 273.819 & 139.680 & 104.233 & 35.161 & 60.566 & 143.185 \\
\hline 14 & 229.555 & 349.032 & 95.603 & 20.047 & 224.895 & 139.826 & 163.484 & 35.249 & 99.160 & 142.637 \\
\hline 15 & 408.708 & 199.218 & 94.793 & 69.507 & 223.647 & 90.048 & 222.821 & 35.035 & 34.289 & 142.813 \\
\hline 16 & 409.009 & 274.461 & 94.783 & 120.265 & 224.447 & 289.530 & 46.073 & 35.050 & 16.403 & 16.093 \\
\hline 17 & 319.324 & 423.606 & 94.803 & 69.505 & 324.296 & 139.724 & 45.118 & 35.004 & 27.117 & 73.502 \\
\hline 18 & 409.174 & 349.304 & 94.776 & 69.594 & 469.443 & 89.984 & 45.043 & 35.066 & 15.594 & 44.985 \\
\hline 19 & 50.019 & 199.425 & 94.995 & 70.084 & 274.228 & 289.226 & 282.004 & 35.074 & 138.649 & 143.550 \\
\hline 20 & 409.072 & 274.738 & 94.801 & 69.838 & 174.355 & 189.540 & 222.792 & 35.243 & 52.524 & 58.134 \\
\hline 21 & 319.252 & 198.770 & 95.208 & 69.919 & 224.434 & 239.368 & 45.052 & 35.022 & 145.296 & 50.771 \\
\hline 22 & 408.780 & 199.649 & 94.587 & 69.719 & 223.288 & 139.596 & 163.533 & 35.074 & 23.587 & 0.814 \\
\hline 23 & 229.948 & 274.441 & 31.281 & 119.662 & 224.488 & 90.843 & 104.347 & 40.366 & 147.501 & 62.377 \\
\hline 24 & 319.176 & 334.651 & 20.783 & 20.084 & 74.685 & 89.384 & 104.262 & 35.038 & 146.505 & 141.502 \\
\hline
\end{tabular}




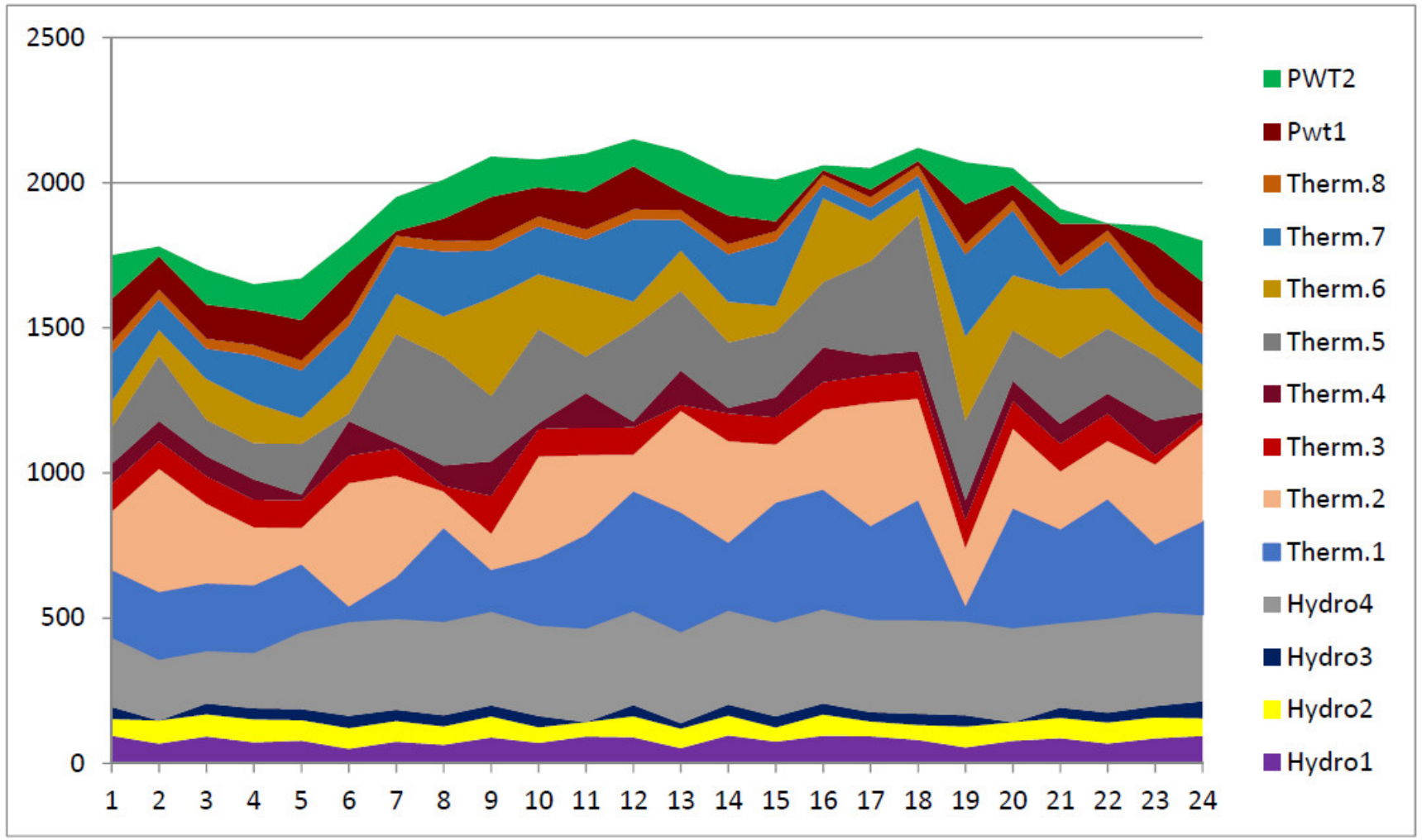

Figure 10. Optimal power generation of thermal and hydro units for Test System 5 for cost-minimizing.

\section{Conclusions}

This study has presented short-term hydrothermal generation scheduling (STHS) with a wind and photovoltaic power integration system using the LAPO algorithm. To examine the effectiveness of the proposed method, five systems comprising a multi-chain cascade of hydropower, different thermal units, wind units, and PV units have been used to analyze the effect of renewable energy sources in solving the STHS problem with wind and PV power integration system. In Test System 2 with the presence of wind and PV, the minimum fuel cost value reduced by $\$ 590.68$ /day compared to Test System 1 . Moreover, total emissions reduced by $2425.42 \mathrm{Ib} /$ day compared to Test System 1. In Test System 4 , the minimum fuel cost reduced by $\$ 3173.6 /$ day compared to Test System 3. In Test System 5, the minimum fuel cost reduced by $\$ 3404 /$ day compared to Test System 3 . The simulation results obtained by the LAPO method prove the efficacy and superiority of the proposed method. In the future, the short-term hydrothermal generation scheduling with integration of renewable energy considering uncertainty using different efficient and recent multi-objective optimization algorithms could be considered.

Author Contributions: Conceptualization, M.M., A.-R.Y. and S.K.; data curation, M.E., and E.E.E.; formal analysis, M.M., A.-R.Y. and S.K.; methodology, M.E., and E.E.E.; software, M.M., A.-R.Y. and S.K.; supervision, M.E., and E.E.E.; validation, M.M., A.-R.Y. and S.K.; visualization, M.E., and E.E.E.; writing—original draft, M.M., A.-R.Y. and S.K.; writing—review and editing, M.E. and E.E.E. All authors together organized and refined the manuscript in the present form. All authors have read and agreed to the published version of the manuscript.

Funding: This work was supported by Taif University Researchers Supporting Project number (TURSP-2020/86): Taif University, Taif, Saudi Arabia.

Institutional Review Board Statement: Not applicable.

Informed Consent Statement: Not applicable.

Data Availability Statement: Not applicable. 
Conflicts of Interest: The authors declare no conflict of interest.

\section{Nomenclature}

\begin{tabular}{|c|c|c|}
\hline \multicolumn{2}{|l|}{$F_{1}$} & Total cost of thermal, wind, and PV-generating units \\
\hline \multicolumn{2}{|l|}{$f_{s i}^{t}$} & Total cost of thermal-generating units \\
\hline \multicolumn{2}{|l|}{$f_{w k}^{t}$} & Total cost of wind-generating units \\
\hline \multicolumn{2}{|l|}{$f_{\text {pom }}^{t}$} & Total cost of PV-generating units. \\
\hline \multicolumn{2}{|l|}{$N_{S}$} & Total number of thermal-generating units \\
\hline \multicolumn{2}{|l|}{$N_{w}$} & Total number of wind-generating units \\
\hline \multicolumn{2}{|l|}{$N_{p v}$} & Total number of PV-generating units \\
\hline \multicolumn{2}{|l|}{$T$} & length of total scheduling period \\
\hline \multicolumn{2}{|l|}{$P_{s i}^{t}$} & Power generation from thermal unit at time $t$ \\
\hline & Power generation from wind unit at time $t$ \\
\hline \multicolumn{2}{|l|}{$\begin{array}{l}w k \\
P_{p v m}^{t}\end{array}$} & Power generation from PV unit at time $t$ \\
\hline \multirow{2}{*}{\multicolumn{2}{|c|}{$\begin{array}{l}a_{i}, b_{i}, c_{i} \\
P^{\min }\end{array}$}} & Fuel cost coefficients of thermal unit \\
\hline & & Minimum power generation limit of thermal unit \\
\hline \multicolumn{2}{|l|}{$d_{i}, e_{i}$} & Valve-point impact coefficients of thermal unit \\
\hline \multicolumn{2}{|l|}{$F_{2}$} & Total amount of emission from all thermal units \\
\hline \multicolumn{2}{|l|}{$\alpha_{i}, \beta_{i}, \gamma_{i}, \eta_{i}, \delta_{i}$} & Emission coefficients of the thermal units \\
\hline \multicolumn{2}{|l|}{$N_{h}$} & Total number of hydropower-generating units \\
\hline \multicolumn{2}{|l|}{$P_{D}^{t}$} & Power load demand of the system at time $t$ \\
\hline \multicolumn{2}{|l|}{$P_{h j}^{t}$} & Power output of hydropower unit at time $t$ \\
\hline \multicolumn{2}{|c|}{$P_{L}^{t}$} & Power losses of the hydrothermal system at time $t$ \\
\hline \multirow{2}{*}{\multicolumn{2}{|c|}{$\begin{array}{l}C_{1 j}, C_{2 j}, C_{3 j}, C_{4 j}, C_{5 j}, C_{6 j} \\
V_{h j}^{t}\end{array}$}} & Power generation coefficients of hydropower unit \\
\hline & & Reservoir storage volume of hydropower unit at time $t$ \\
\hline \multicolumn{2}{|c|}{$Q_{h j}^{t}$} & Water discharge rate of hydropower unit at time $t$ \\
\hline \multirow{3}{*}{$\begin{array}{l}{ }_{L} \\
B_{i j}, B_{o i}, B_{o o} \\
I_{h j}^{t}\end{array}$} & \multicolumn{2}{|c|}{ Power transmission loss of the system at time $t$} \\
\hline & \multicolumn{2}{|c|}{ Coefficients of power transmission loss } \\
\hline & \multicolumn{2}{|c|}{ External inflow to reservoir at time $t$} \\
\hline$S_{h j}^{t}$ & \multicolumn{2}{|c|}{ Spillage discharge rate of reservoir at time $t$} \\
\hline$R_{u j}$ & Numbe & r of upstream hydropower unit \\
\hline$V_{h j}^{\text {min }}$ & Minim & am storage volume of hydropower unit \\
\hline$V_{h j}^{\max }$ & Maxim & um storage volume of hydropower unit \\
\hline$Q_{h j}^{\min }$ & Minim & am water discharge of hydropower unit \\
\hline$Q_{h j}^{\max }$ & Maxim & um water discharge of hydropower unit \\
\hline$P_{h j}^{\min }, P_{h j}^{\max }$ & $\begin{array}{l}\text { Minim } \\
\text { of hydr }\end{array}$ & $\begin{array}{l}\text { am and maximum power generation } \\
\text { opower unit }\end{array}$ \\
\hline$P_{s i}^{\min }, P_{s i}^{\max }$ & Minimu & Im and maximum power generation of thermal unit \\
\hline$K_{w k}$ & Direct & ost coefficient for wind power \\
\hline$P_{w r k}^{t}$ & Rated $\mathrm{p}$ & ower of wind-generating unit \\
\hline$v_{\text {in }}$ & Cut in & wind speed \\
\hline$v_{\text {out }}$ & Cut out & wind speed \\
\hline$v_{r}$ & Rated v & vind speed \\
\hline$K_{s m}$ & Direct c & ost coefficient for PV power \\
\hline G & Forecas & t solar radiation \\
\hline$G_{\text {std }}$ & Solar ra & Idiation in the standard environment \\
\hline$R_{C}$ & A certa & in radiation point \\
\hline$P_{s r}$ & Equiva & lent rated power output of the PV unit \\
\hline
\end{tabular}




\section{References}

1. Homem-de-Mello, T.; de Matos, V.L.; Finardi, E.C. Sampling strategies and stopping criteria for stochastic dual dynamic programming: A case study in long-term hydrothermal scheduling. Energy Syst. 2011, 2, 1-31. [CrossRef]

2. Ahmadi, A.; Aghaei, J.; Shayanfar, H.A.; Rabiee, A. Mixed integer programming of multiobjective hydro-thermal self scheduling. Appl. Soft Comput. 2012, 12, 2137-2146. [CrossRef]

3. Sawa, T.; Sato, Y.; Tsurugai, M.; Onishi, T. Daily integrated generation scheduling for thermal, pumped-storage, and cascaded hydro units and purchasing power considering network constraints. Electr. Eng. Jpn. 2011, 175, 25-34. [CrossRef]

4. Dieu, V.N.; Ongsakul, W. Improved merit order and augmented Lagrange Hopfield network for short term hydrothermal scheduling. Energy Convers. Manag. 2009, 50, 3015-3023. [CrossRef]

5. Haghrah, A.; Mohammadi-ivatloo, B.; Seyedmonir, S. Real coded genetic algorithm approach with random transfer vectors-based mutation for short-term hydro-thermal scheduling. IET Gener. Transm. Distrib. 2014, 9, 75-89. [CrossRef]

6. Zhang, J.; Lin, S.; Qiu, W. A modified chaotic differential evolution algorithm for short-term optimal hydrothermal scheduling. Int. J. Electr. Power Energy Syst. 2015, 65, 159-168. [CrossRef]

7. Mahor, A.; Rangnekar, S. Short term generation scheduling of cascaded hydro electric system using novel self adaptive inertia weight PSO. Int. J. Electr. Power Energy Syst. 2012, 34, 1-9. [CrossRef]

8. Roy, P.K. Teaching learning based optimization for short-term hydrothermal scheduling problem considering valve point effect and prohibited discharge constraint. Int. J. Electr. Power Energy Syst. 2013, 53, 10-19. [CrossRef]

9. Liao, X.; Zhou, J.; Ouyang, S.; Zhang, R.; Zhang, Y. An adaptive chaotic artificial bee colony algorithm for short-term hydrothermal generation scheduling. Int. J. Electr. Power Energy Syst. 2013, 53, 34-42. [CrossRef]

10. Nazari-Heris, M.; Babaei, A.F.; Mohammadi-Ivatloo, B.; Asadi, S. Improved harmony search algorithm for the solution of non-linear non-convex short-term hydrothermal scheduling. Energy 2018, 151, 226-237. [CrossRef]

11. Rasoulzadeh-Akhijahani, A.; Mohammadi-Ivatloo, B. Short-term hydrothermal generation scheduling by a modified dynamic neighborhood learning based particle swarm optimization. Int. J. Electr. Power Energy Syst. 2015, 67, 350-367. [CrossRef]

12. Nazari-Heris, M.; Mohammadi-Ivatloo, B.; Haghrah, A. Optimal short-term generation scheduling of hydrothermal systems by implementation of real-coded genetic algorithm based on improved Mühlenbein mutation. Energy 2017, 128, 77-85. [CrossRef]

13. Wang, Y.; Zhou, J.; Mo, L.; Zhang, R.; Zhang, Y. Short-term hydrothermal generation scheduling using differential real-coded quantum-inspired evolutionary algorithm. Energy 2012, 44, 657-671. [CrossRef]

14. Zhang, H.; Yue, D.; Xie, X.; Dou, C.; Sun, F. Gradient decent based multi-objective cultural differential evolution for short-term hydrothermal optimal scheduling of economic emission with integrating wind power and photovoltaic power. Energy 2017, 122, 748-766. [CrossRef]

15. Banerjee, S.; Dasgupta, K.; Chanda, C.K. Short term hydro-wind-thermal scheduling based on particle swarm optimization technique. Int. J. Electr. Power Energy Syst. 2016, 81, 275-288. [CrossRef]

16. Dubey, H.M.; Pandit, M.; Panigrahi, B. Hydro-thermal-wind scheduling employing novel ant lion optimization technique with composite ranking index. Renew. Energy 2016, 99, 18-34. [CrossRef]

17. Yuan, X.; Tian, H.; Yuan, Y.; Huang, Y.; Ikram, R.M. An extended NSGA-III for solution multi-objective hydro-thermal-wind scheduling considering wind power cost. Energy Convers. Manag. 2015, 96, 568-578. [CrossRef]

18. Zhou, J.; Lu, P.; Li, Y.; Wang, C.; Yuan, L.; Mo, L. Short-term hydro-thermal-wind complementary scheduling considering uncertainty of wind power using an enhanced multi-objective bee colony optimization algorithm. Energy Convers. Manag. 2016, 123, 116-129. [CrossRef]

19. Li, C.; Wang, W.; Chen, D. Multi-objective complementary scheduling of hydro-thermal-RE power system via a multi-objective hybrid grey wolf optimizer. Energy 2019, 171, 241-255. [CrossRef]

20. Nematollahi, A.F.; Rahiminejad, A.; Vahidi, B. A novel physical based meta-heuristic optimization method known as lightning attachment procedure optimization. Appl. Soft Comput. 2017, 59, 596-621. [CrossRef]

21. Nematollahi, A.F.; Rahiminejad, A.; Vahidi, B. A novel multi-objective optimization algorithm based on Lightning Attachment Procedure Optimization algorithm. Appl. Soft Comput. 2019, 75, 404-427. [CrossRef]

22. Taher, M.A.; Kamel, S.; Jurado, F.; Ebeed, M. Optimal power flow solution incorporating a simplified UPFC model using lightning attachment procedure optimization. Int. Trans. Electr. Energy Syst. 2019, 30, 12170. [CrossRef]

23. Youssef, H.; Kamel, S.; Ebeed, M. Optimal Power Flow Considering Loading Margin Stability Using Lightning Attachment Optimization Technique. In Proceedings of the 2018 Twentieth International Middle East Power Systems Conference (MEPCON), Cairo, Egypt, 18-20 December 2018; pp. 1053-1058.

24. Hashemian, P.; Nematollahi, A.F.; Vahidi, B. A novel approach for optimal DG allocation in distribution network for minimizing voltage sag. Adv. Energy Res. 2019, 6, 55-73.

25. Liu, W.; Yang, S.; Ye, Z.; Huang, Q.; Huang, Y. An Image Segmentation Method Based on Two-Dimensional Entropy and Chaotic Lightning Attachment Procedure Optimization Algorithm. Int. J. Pattern Recognit. Artif. Intell. 2017, 34, 2054030. [CrossRef]

26. Dubey, H.M.; Pandit, M.; Panigrahi, B. Ant lion optimization for short-term wind integrated hydrothermal power generation scheduling. Int. J. Electr. Power Energy Syst. 2016, 83, 158-174. [CrossRef]

27. Lu, S.; Sun, C. Quadratic approximation based differential evolution with valuable trade off approach for bi-objective short-term hydrothermal scheduling. Expert Syst. Appl. 2011, 38, 13950-13960. [CrossRef] 
28. Basu, M. Fast convergence real-coded genetic algorithm for short-term solar-wind-hydro-thermal generation scheduling. Electr. Power Compon. Syst. 2018, 46, 1239-1249. [CrossRef]

29. Basu, M. Improved differential evolution for short-term hydrothermal scheduling. Int. J. Electr. Power Energy Syst. 2014, 58, 91-100. [CrossRef]

30. Wu, Y.; Wu, Y.; Liu, X. Couple-based particle swarm optimization for short-term hydrothermal scheduling. Appl. Soft Comput. 2019, 74, 440-450. [CrossRef]

31. Zhou, J.; Liao, X.; Ouyang, S.; Zhang, R.; Zhang, Y. Multi-objective artificial bee colony algorithm for short-term scheduling of hydrothermal system. Int. J. Electr. Power Energy Syst. 2014, 55, 542-553. [CrossRef]

32. Tian, H.; Yuan, X.; Ji, B.; Chen, Z. Multi-objective optimization of short-term hydrothermal scheduling using non-dominated sorting gravitational search algorithm with chaotic mutation. Energy Convers. Manag. 2014, 81, 504-519. [CrossRef]

33. Selvakumar, A.I. Civilized swarm optimization for multiobjective short-term hydrothermal scheduling. Int. J. Electr. Power Energy Syst. 2013, 51, 178-189. [CrossRef]

34. Basu, M. An interactive fuzzy satisfying method based on evolutionary programming technique for multiobjective short-term hydrothermal scheduling. Electr. Power Syst. Res. 2004, 69, 277-285. [CrossRef]

35. Fang, N.; Zhou, J.; Zhang, R.; Liu, Y.; Zhang, Y. A hybrid of real coded genetic algorithm and artificial fish swarm algorithm for short-term optimal hydrothermal scheduling. Int. J. Electr. Power Energy Syst. 2014, 62, 617-629. [CrossRef]

36. Kang, C.; Guo, M.; Wang, J. Short-term hydrothermal scheduling using a two-stage linear programming with special ordered sets method. Water Resour. Manag. 2017, 31, 3329-3341. [CrossRef]

37. Sun, C.; Lu, S. Short-term combined economic emission hydrothermal scheduling using improved quantum-behaved particle swarm optimization. Expert Syst. Appl. 2010, 37, 4232-4241. [CrossRef]

38. Nazari-Heris, M.; Mohammadi-Ivatloo, B.; Gharehpetian, G. Short-term scheduling of hydro-based power plants considering application of heuristic algorithms: A comprehensive review. Renew. Sustain. Energy Rev. 2017, 74, 116-129. [CrossRef]

39. Bhattacharjee, K.; Bhattacharya, A.; Dey, S.H.N. Real coded chemical reaction based optimization for short-term hydrothermal scheduling. Appl. Soft Comput. 2014, 24, 962-976. [CrossRef]

40. James, J.; Li, V.O. A social spider algorithm for global optimization. Appl. Soft Comput. 2015, 30, 614-627.

41. Swain, R.; Barisal, A.; Hota, P.; Chakrabarti, R. Short-term hydrothermal scheduling using clonal selection algorithm. Int. J. Electr. Power Energy Syst. 2011, 33, 647-656. [CrossRef]

42. Lakshminarasimman, L.; Subramanian, S. Short-term scheduling of hydrothermal power system with cascaded reservoirs by using modified differential evolution. IEE Proc. Gener. Transm. Distrib. 2006, 153, 693-700. [CrossRef]

43. Mandal, K.; Chakraborty, N. Differential evolution technique-based short-term economic generation scheduling of hydrothermal systems. Electr. Power Syst. Res. 2008, 78, 1972-1979. [CrossRef]

44. Zhang, J.; Wang, J.; Yue, C. Small population-based particle swarm optimization for short-term hydrothermal scheduling. IEEE Trans. Power Syst. 2011, 27, 142-152. [CrossRef] 